\title{
Contribution of SST change to multidecadal global and continental surface air temperature trends between 1910 and 2013
}

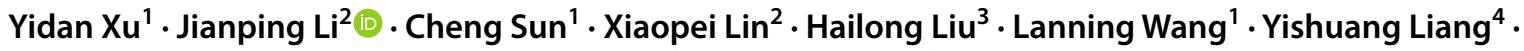 \\ Qiuyun Wang ${ }^{1} \cdot$ Yazhou Zhang ${ }^{1} \cdot$ Zhaolu Hou $^{2} \cdot$ Fuchang Wang $^{3}$
}

Received: 23 July 2019 / Accepted: 14 November 2019 / Published online: 23 November 2019

(C) The Author(s) 2019

\begin{abstract}
The global mean surface air temperature (GMST) shows multidecadal variability over the period of 1910-2013, with an increasing trend. This study quantifies the contribution of hemispheric surface air temperature (SAT) variations and individual ocean sea surface temperature (SST) changes to the GMST multidecadal variability for 1910-2013. At the hemispheric scale, both the Goddard Institute for Space Studies (GISS) observations and the Community Earth System Model (CESM) Community Atmosphere Model 5.3 (CAM5.3) simulation indicate that the Northern Hemisphere (NH) favors the GMST multidecadal trend during periods of accelerated warming (1910-1945, 1975-1998) and cooling (1940-1975, 2001-2013), whereas the Southern Hemisphere (SH) slows the intensity of both warming and cooling processes. The contribution of the NH SAT variation to the GMST multidecadal trend is higher than that of the SH. We conduct six experiments with different ocean SST forcing, and find that all the oceans make positive contributions to the GMST multidecadal trend during rapid warming periods. However, only the Indian, North Atlantic, and western Pacific oceans make positive contributions to the GMST multidecadal trend between 1940 and 1975, whereas only the tropical Pacific and the North Pacific SSTs contribute to the GMST multidecadal trend between 2001 and 2013. The North Atlantic and western Pacific oceans have important impacts on modulating the GMST multidecadal trend across the entire 20th century. Each ocean makes different contributions to the SAT multidecadal trend of different continents during different periods.
\end{abstract}

Keywords Multidecadal surface air temperature trend $\cdot$ Sea surface temperature change $\cdot$ Contribution rate $\cdot$ Model simulation $\cdot$ Hemisphere properties $\cdot$ Continental surface air temperature trend

\section{Introduction}

An apparent global mean surface air temperature (GMST) slowdown, known as the 'global warming hiatus', occurred between 2001 to 2013 (Kosaka and Xie 2013; England et al. 2014; Fyfe and Gillett 2014; Santer et al. 2014;

Jianping Li

ljp@ouc.edu.cn

1 College of Global Change and Earth System Science, Beijing Normal University, Beijing 100875, China

2 Key Laboratory of Physical Oceanography/Institute for Advanced Ocean Studies, Ocean University of China and Qingdao National Laboratory for Marine Science and Technology, Qingdao 266100, China

3 Institute of Oceanography, Shanghai Jiao Tong University, Shanghai 200030, China

4 Tsinghua University, Beijing 100084, China
Sillmann et al. 2014; Smith 2013; Trenberth and Fasullo 2013). This global warming hiatus exhibits a substantial decadal cooling temperature trend, following a welldefined rapid warming trend throughout the 20th century accompanied by a long-term carbon dioxide $\left(\mathrm{CO}_{2}\right.$; Meinshausen et al. 2017) increase (Fig. 1) (IPCC 2007; Stocker et al. 2014; Trenberth 2015; Trenberth and Fasullo 2013). The global warming hiatus has received much attention since 2009 (Easterling and Wehner 2009). The generative mechanisms of this phenomenon can be divided into two main schools of thought. One proposes external forcing effects, including the solar cycle variation (Knight et al. 2009), the stratospheric aerosols increasing induced by volcanic eruptions (Jónsson et al. 1996; Ramaswamy et al. 2006; Sato et al. 1993; Santer et al. 2014), and stratospheric water vapor decrease between 2000 and 2009 (Solomon et al. 2010). The other proposes that climate internal variability, such as sea surface temperature (SST) 
Fig. 1 Observed global mean surface air temperature (GMST; blue; ${ }^{\circ} \mathrm{C}$ ) anomalies and global atmospheric $\mathrm{CO}_{2}$ concentration (black; ppmv) time series from 1910 to 2017. The GMST is derived from the GISTEMP dataset, relative to the base period 1951-1980. The global atmospheric $\mathrm{CO}_{2}$ concentration is obtained from a suite of atmospheric concentration observations and emissions estimates for greenhouse gases (Meinshausen et al. 2017)

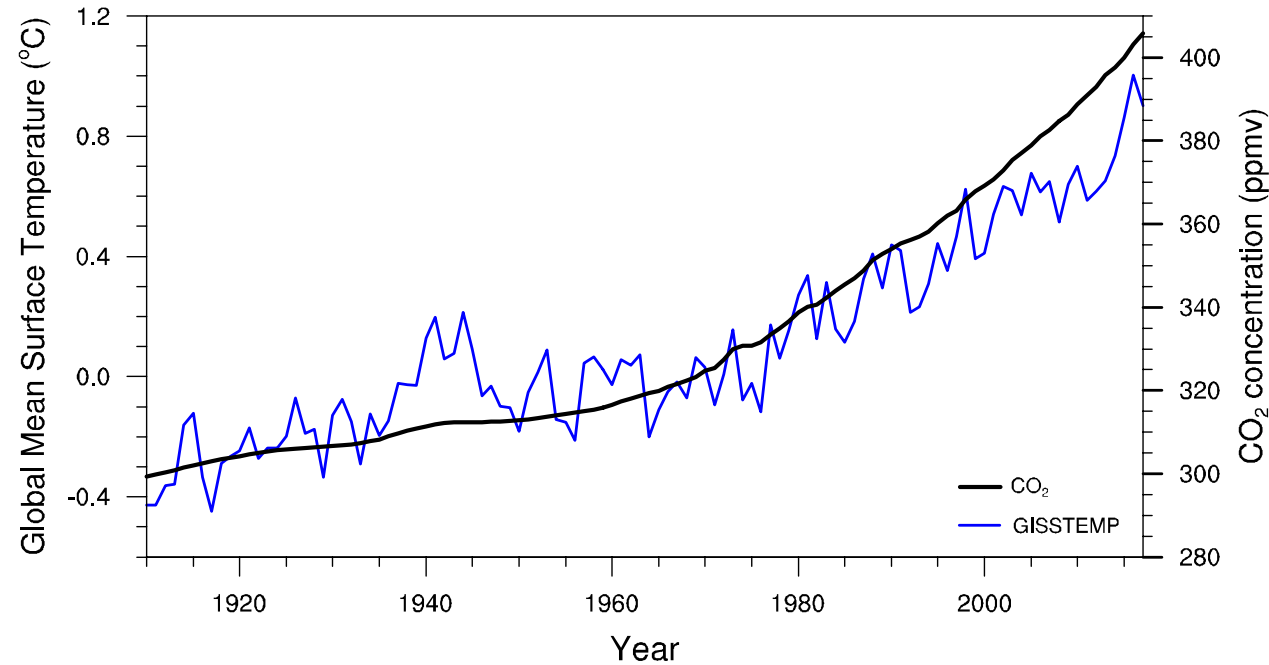

variations (Kosaka and Xie 2013; England et al. 2014; Trenberth and Fasullo 2013) and energy redistribution (Meehl et al. 2011, 2013) in the climate system are the major causes.

From the perspective of the importance of SST variation on the GMST decadal trend, previous studies have mainly focused on the tropical Pacific Ocean (Kosaka and Xie 2013; England et al. 2014) and the Atlantic ocean (Li et al. 2013, 2018; Sun et al. 2015). For example, the global warming hiatus is tied specifically to a La-Niñalike decadal cooling and is part of the internal variability of the climate (Kosaka and Xie 2013, 2016; Xie et al. 2016; Xie and Kosaka 2017), and the changes in SST in the eastern tropical Pacific play a key role in modulating GMST variability (England et al. 2014; Li et al. 2015, 2017; Yao et al. 2017; Zhang et al. 2010). The enhanced Atlantic warming since the early 1990s could amplify the eastern Pacific cooling and further offset the GMST warming (McGregor et al. 2014). The teleconnection between the Atlantic and western Pacific ocean and decadal climate variability also make a considerable contribution to GMST variations (Clement and DiNezio 2014; Li et al. 2016; Sun et al. 2017). In addition, the interaction between the surface layers of the Indian and Pacific oceans (0-300 m) can also influence the GMST trend (Mochizuki et al. 2016; Nidheesh et al. 2013; Nieves et al. 2015; Timmermann et al. 2010).

A wide range of studies have demonstrated that distinct ocean modes have certain relevance to the decadal to multidecadal trend of GMST, for example, the Interdecadal Pacific Oscillation (Minobe and Mantua 1999; Power et al. 1999; Zhang et al. 1997; England et al. 2014) phase shifts are associated with decadal GMST shifts (Chen and Wallace 2015; Dai et al. 2015; England et al. 2014; Maher et al. 2014; Trenberth and Fasullo 2013) and the Atlantic Multidecadal Oscillation and the Interdecadal Pacific Oscillation together account for $88 \%$ of the decadal GMST variations (Dai et al. 2015).

Although many studies have clarified the effects of distinct SSTs and ocean modes on the GMST multidecadal trend, it is still necessary to systematically analyze the impact of key regions on the GMST multidecadal trend. In addition, the contribution of SST variability from different regions to GMST multidecadal trend is distinct during different periods. On this basis, we carry out a series of atmospheric general circulation model (AGCM) SST forcing experiments to quantify the effect of regional SSTs corresponding to the ocean modes of the same regions on the GMST multidecadal trend during the periods 1910-1945, 1940-1975, 1975-1998, and 2001-2013, and quantify the continental surface air temperature (SAT) trends tied to regional SST variation.

Furthermore, at hemispheric scales, the distributions of ocean and land on Earth are asymmetrical with respect to the hemispheres; that is, the Northern Hemisphere (NH) comprises $60.7 \%$ ocean and $39.3 \%$ land, whereas the Southern Hemisphere (SH) comprises $80.9 \%$ ocean and $19.1 \%$ land. The temporal properties of the SAT multidecadal trend of the land and ocean in the $\mathrm{NH}$ and $\mathrm{SH}$ has been discussed in previous research (Xing et al. 2017). However, it is also important to determine the spatial SAT variation for the NH and $\mathrm{SH}$, and the contribution of both hemispheric distinct SAT multidecadal variations to the GMST multidecadal trend.

The remainder of this study is organized as follows. In Sect. 2, we introduce the data, model simulation setup, and methods of analysis. Section 3 presents a comparison of the model simulations with the observations. Then, in Sect. 4, we discuss the distinct contribution of NH and SH SAT variability to GMST and land surface air temperature (LSAT) multidecadal trends, and the effects of different regional SST changes on GMST and LSAT multidecadal trends are 
illustrated, and the multidecadal continental SAT multidecadal trends tied to regional SST change are discussed. Finally, a summary of the main conclusions and discussion are presented in Sect. 5 .

\section{Data and methodology}

\subsection{Data}

This study uses data from the National Aeronautics and Space Administration (NASA) Goddard Institute for Space Studies surface temperature analysis for the globe (GISSTEMP), monthly data for $1910-2017$ on a $2^{\circ}$ latitude $\times 2^{\circ}$ longitude grid $(360 \times 180)$ spatial coverage (Hansen et al. 2010). Monthly data of global mean atmospheric $\mathrm{CO}_{2}$ concentration for 1910-2014 are obtained from the historical Coupled Model Intercomparison Project Phase 6 (CMIP6) greenhouse gas concentrations (Meinshausen et al. 2017). The $\mathrm{CO}_{2}$ concentrations for the period 2015-2017 are obtained from the Scenario, AIM-ssp370, GCAM4-ssp434, and REMIND-MAGPIE-ssp534-over models from CMIP6 at the same resolution as the historical $\mathrm{CO}_{2}$ concentration data (Meinshausen et al. 2017).

\subsection{AGCM simulations}

The climate model used in this study is the atmospheric component of the Community Earth System Model version 1.2.2 (CESM1.2.2), the Community Atmosphere Model version 5.3 (CAM5.3; Hurrell et al. 2013). The model is formulated in terms of an $F$ component set, which means that the atmosphere is coupled with an active land model (CLM), a thermodynamics-only sea ice model (CICE), and a data ocean model (DOCN). We conduct a series of AGCM simulations from 1850 to 2017 (with 60 years as the model spin-up) to ascertain the quantitative contributions of observed global and individual ocean SST changes to the global and continental multidecadal SAT trend. The simulations are forced by the observed solar cycle and the atmospheric composition changes including greenhouse gases, aerosols, and volcanic aerosols from 1850 to 2005 . We use Representative Concentration Pathway scenario 4.5 (RCP4.5; Meehl et al. 2012) to simulate radiative forcing between 2006 and 2017. This scenario is selected because the concentration of $\mathrm{CO}_{2}$ in RCP4.5 increases at a moderate rate, such that internal variability can occasionally offset the radiative warming effects and produce a decade with negative anomalies in the SAT trend (Meehl et al. 2011). We also use the observed SST dataset covering the period 1850-2017. One simulation uses the observed SST to force the global ocean basins (control experiment) and the other six experiments use the observed SST to force the specified ocean basins while including climatological SST forcing for the other basins (sensitivity experiments). Here, we select six key ocean regions for simulation based on the corresponding ocean basins in which the location of dominant SST modes are included and the mainly SST features have been paid attention in previous studies (England et al. 2014; Luo et al. 2012; Mantua et al. 1997; Nan and Li 2003; Trenberth and Hurrell 1994; Trenberth and Fasullo 2013; Sun et al. 2017; Yao et al. 2017). We select the North Atlantic Ocean (NA; $0^{\circ}-60^{\circ} \mathrm{N}, 80^{\circ} \mathrm{W}-0^{\circ}$ ) and the North Pacific Ocean (NP; $20^{\circ}-70^{\circ} \mathrm{N}, 110^{\circ} \mathrm{E}-100^{\circ} \mathrm{W}$ ) basins following the main regions where AMO and PDO located respectively. The eastern tropical Pacific Ocean (TP; $10^{\circ} \mathrm{S}-10^{\circ} \mathrm{N}$, $180^{\circ}-90^{\circ} \mathrm{W}$ ) is selected because this region is the key area in which ENSO is located, and because the recent warming hiatus featured a decadal La-Niña-like spatial pattern (England et al. 2014; Kosaka and Xie 2013; Trenberth and Fasullo 2013). The western Pacific Ocean (WP; $20^{\circ} \mathrm{S}-20^{\circ}$ $\mathrm{N}, 120^{\circ} \mathrm{E}-180^{\circ}$ ) is an important source of heat and moisture for the atmospheric circulation (Sun et al. 2017), and is selected based on the $28.5^{\circ} \mathrm{C}$ isotherm covering region in winter as previous study has shown (Qiang and Yang, 2013). Also, the Indian Ocean (IO; $20^{\circ} \mathrm{S}-20^{\circ} \mathrm{N}, 40^{\circ}-120^{\circ} \mathrm{E}$ ) and the western Pacific Ocean are selected based on the region's selection criteria by Luo et al. (2012) and Yao et al. (2017). The Southern Ocean $\left(\mathrm{SO} ; 40^{\circ}-70^{\circ} \mathrm{S}, 0^{\circ}-360^{\circ}\right)$ is selected based on the Southern Hemisphere annular mode region (Nan and Li 2003) (Fig. 2). The specific ocean basins have clear impact on the local and global climate (McGregor et al. 2014; Sun et al. 2017). For convenience of discussion, we use 'NA' to represent the NA SST forcing experiment in this article, with the same approach for NP, TP, WP, IO, and SO.

\subsection{Statistical method}

Following previous studies (England et al. 2014; Xing et al. 2017; Yao et al. 2017; Zuo et al. 2019), we analyze two periods of rapid global temperature warming (1910-1945 and 1975-1998) and two periods of global cooling, or at least a slowdown in warming (1940-1975 and 2001-2013). The contribution rate is defined here as the percentage of SAT multidecadal trend of the factor $A$ divided by the SAT multidecadal trend of global; that is, the percentage contribution of A's SAT multidecadal trend to the GMST multidecadal trend. To further quantify the contribution rate of each parameter of interest in each period, and also in consideration of the fact that some of the observational data are missing in some regions, we calculate the contribution rate of the hemispheric SAT multidecadal trend to the GMST multidecadal trend during the acceleration and slowdown periods using the valid rate at each grid cell and area weight determined using the following equations: 
Fig. 2 Selected basins where observed SST is specified in the CESM_CAM5.3 model experiments. The six colored boxes are the North Pacific Ocean (NP; golden), North Atlantic Ocean (NA; green), eastern tropical Pacific Ocean (TP; blue), western Pacific Ocean (WP; red), Indian Ocean (IO; magenta), and Southern Ocean (SO; cyan)

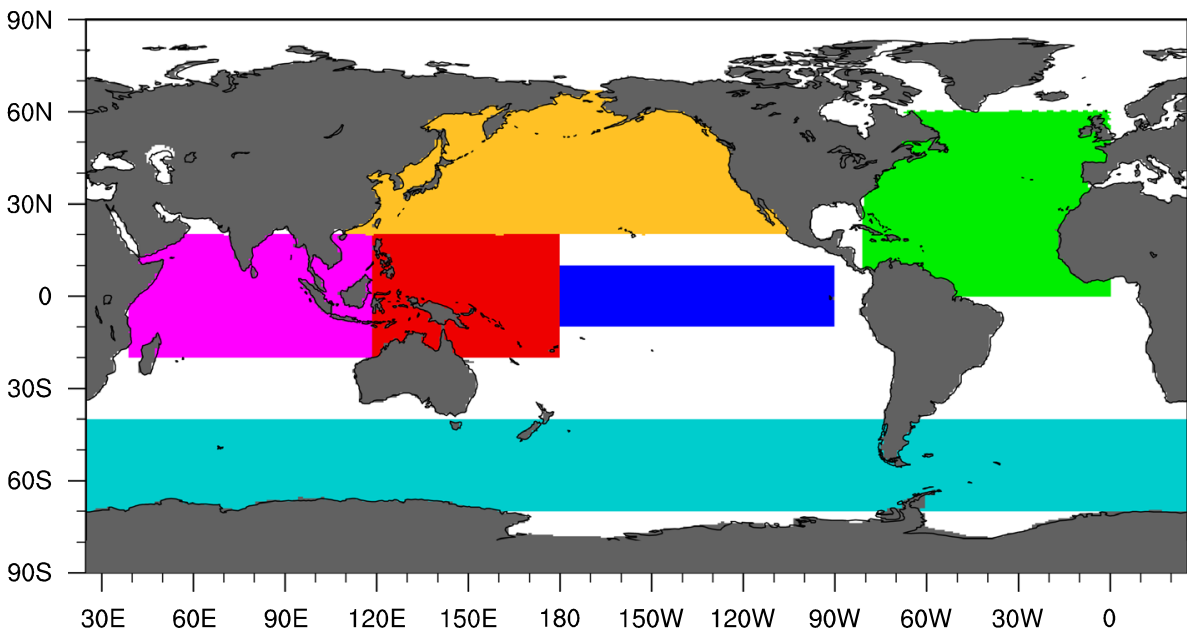

$T_{r t i}=T_{t t i} \times \frac{\operatorname{num}(i)}{\operatorname{num}(G)}$

$C r_{i}=\frac{T_{r t i}}{T_{r t G}} \times 100 \%$

where $T_{r t i}$ is the hemispheric SAT multidecadal trend; $T_{t t i}$ indicates the true value of the hemispheric SAT multidecadal trend with a weighted area average; num represents the number of grid points for which data are present; $G$ and $i$ represent global and individual hemisphere, respectively; $T_{r t G}$ is the GMST multidecadal trend with a weighted area average; and $\mathrm{Cr}_{i}$ represents the hemispheric contribution rate. A large model bias is present in the high latitudes of the $\mathrm{SH}$ between 2001 and 2013, and thus the multidecadal trends from these areas are removed prior to analysis. The sum of contribution rates of the $\mathrm{NH}$ and SH SAT multidecadal trend to the GMST multidecadal trend equals 1 , whereas their separate contribution could be less than 0 .

The contribution of the individual ocean SST forcing to the GMST variation is calculated as follows:

$C r_{i}=\frac{T_{i}}{T(O)} \times 100 \%, \sum r_{i} \neq 1$

where $\mathrm{Cr}_{i}$ is the contribution rate (the percentage contribution) of the individual ocean SST forcing experiment's SAT multidecadal trend to the GMST multidecadal trend, $T_{i}$ indicates the SAT response to individual ocean SST forcing, and $T(O)$ is the SAT response to the historical SST forcing for global ocean basin; that is, $T(O)$ is the combined linear effects of each individual ocean's SST forcing experiments and the ocean's nonlinear interactions. Area weight is used in calculation and nonlinear effects are not taken into account here. Thus, the sum of the contribution rates from the various ocean SST forcing experiments might exceed $100 \%$, and this can be explained as the result of nonlinear climate effects and model biases. Least-squares methods are used in all SAT multidecadal trend calculations, and a twotailed Student's $t$ test is used to test for statistical significance. The percentage of sign consistency of the individual ocean SST forcing experiments with the GMST multidecadal trend is also calculated, but only for specific regions for which observations are available.

\section{Model performance}

Here, the performance of the CESM_CAM5.3 model (control experiment) is evaluated using a suite of statistical techniques. Figure 3 compares the time series of the observed and simulated SAT for the period 1910-2017. The model reproduces the observed record of both GMST and global land surface air temperature (LSAT) reasonably well. For GMST, all correlation coefficients between the observed and simulated data are greater than 0.96 at the global and hemispheric scales, and the root-mean-square errors (RMSE) are less than 0.10. For LSAT, the model reproduces the observations with correlation coefficients above 0.89 in the $\mathrm{SH}$, and this is accompanied by an RMSE of $0.18^{\circ} \mathrm{C}$. As for global LSAT, the correlation coefficient reaches 0.95 , accompanied by an RMSE of $0.16{ }^{\circ} \mathrm{C}$. A comparison of the spatial trend between 1910 and 2013 shows high consistency between the simulated and observed results (Fig. 4).

Considering the spatial variability of the four periods of warming and cooling identified above, Fig. 5 shows the spatial variations of the GMST over these four periods in the observations (Fig. 5a-d) and simulations (Fig. 5e-h). Except for Eurasia, the observed spatial variations of the four periods are reproduced well for most regions around the globe in the CESM_CAM5.3 model. The model performs better in the periods of accelerated warming (1910-1945 and 1975-1998) than in the two periods of cooling (1940-1975 and 2001-2013). The observed and simulated GMST 

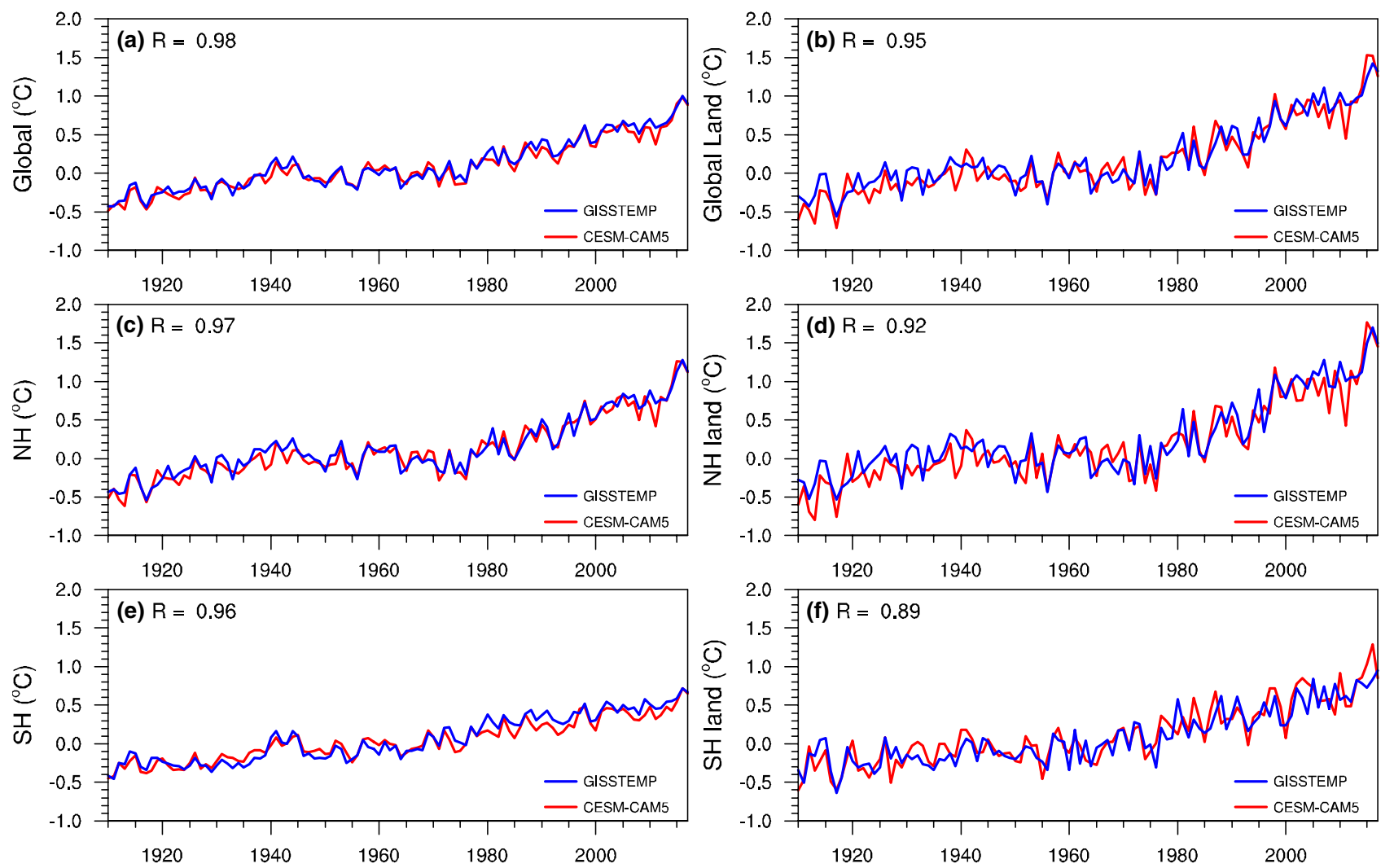

Fig. 3 Time series of the observed (GISSTEMP; blue line) and simulated (CESM_CAM5.3; red line) SAT for 1910-2017. Units: ${ }^{\circ} \mathrm{C}$. a GMST, b global LSAT, c NH SAT, d NH LSAT, e SH SAT, and f SH

LSAT. In all panels, the correlation coefficients $(R)$ are significant at the 99\% level (Student's $t$ test)

multidecadal spatial variations both reveal a flat accelerated warming trend over the two warming periods except for some mid-latitude regions (Fig. 5a, c, e, g). The percentage of sign consistency in the GMST spatial variations between the model and observation records is over $78 \%$ (76.7\% for land percentage of sign consistency) during the accelerated warming periods. During 1940-1975 and 2001-2013, the observed and simulated GMST multidecadal spatial variations both show an explicit cooling signal over ocean and land. The tropical Pacific Ocean presents a cooling pattern and the mid-high latitude in the North American landmass also reveals cooling characteristics during these periods (Fig. 5b, d, f, h). Although more discrepancies are found between the simulation and observations in cooling periods compared with the accelerated warming periods, the percentage of sign consistency in the GMST spatial variations between the model and observation record is still over 59.8\% (50.5\% for land percentage of sign consistency) (Table 1). This indicates that even though there are some regions, such as Eurasia, where the model could not accurately reproduce the observed spatial variation, the model is capable of simulating GMST trends that are temporally and spatially consistent with the observations over the period 1910-2013.

In addition, it could capture the main characteristics of the spatial distribution of SAT variations in the four periods (Fig. 5). Therefore, the model can help to improve our understanding of the relationship between the regional SAT and the GMST, as well as the contribution of the various ocean basins to the GMST trend.

\section{Results}

\subsection{Contribution of NH and SH SAT variability to the GMST (LSAT) multidecadal trend}

Figure 6 shows the GMST and LSAT trends for different periods from the observations and model simulation (control experiment). The observed GMST trends over 1910-1945 and 1975-1998 are $+0.137{ }^{\circ} \mathrm{C} \mathrm{decade}{ }^{-1}(+$ $0.136{ }^{\circ} \mathrm{C}$ decade $^{-1}$ in simulation) and $+0.187^{\circ} \mathrm{C} \mathrm{decade}^{-1}$ ( $+0.187{ }^{\circ} \mathrm{C}$ decade $^{-1}$ in simulation) respectively, much higher than over the periods of reduce warming; i.e., 1940-1975 (-0.021 ${ }^{\circ} \mathrm{C}$ decade $\left.^{-1}\right)$ and 2001-2013 (+ $0.039^{\circ} \mathrm{C}$ decade $^{-1}$ ) for the global scale, and similar results are found for LSAT. The GMST (LSAT) trends show an 
Fig. 4 Observed and simulated GMST trends for the period 1910-2005. Units: ${ }^{\circ} \mathrm{C} 100 \mathrm{yr}^{-1}$. a GISSTEMP observed, and b) CESM_CAM5.3 simulated. Shading indicates the GMST trend for each decade. Stippling indicates regions exceeding the 95\% confidence level (Student's $t$ test). White areas indicate missing values
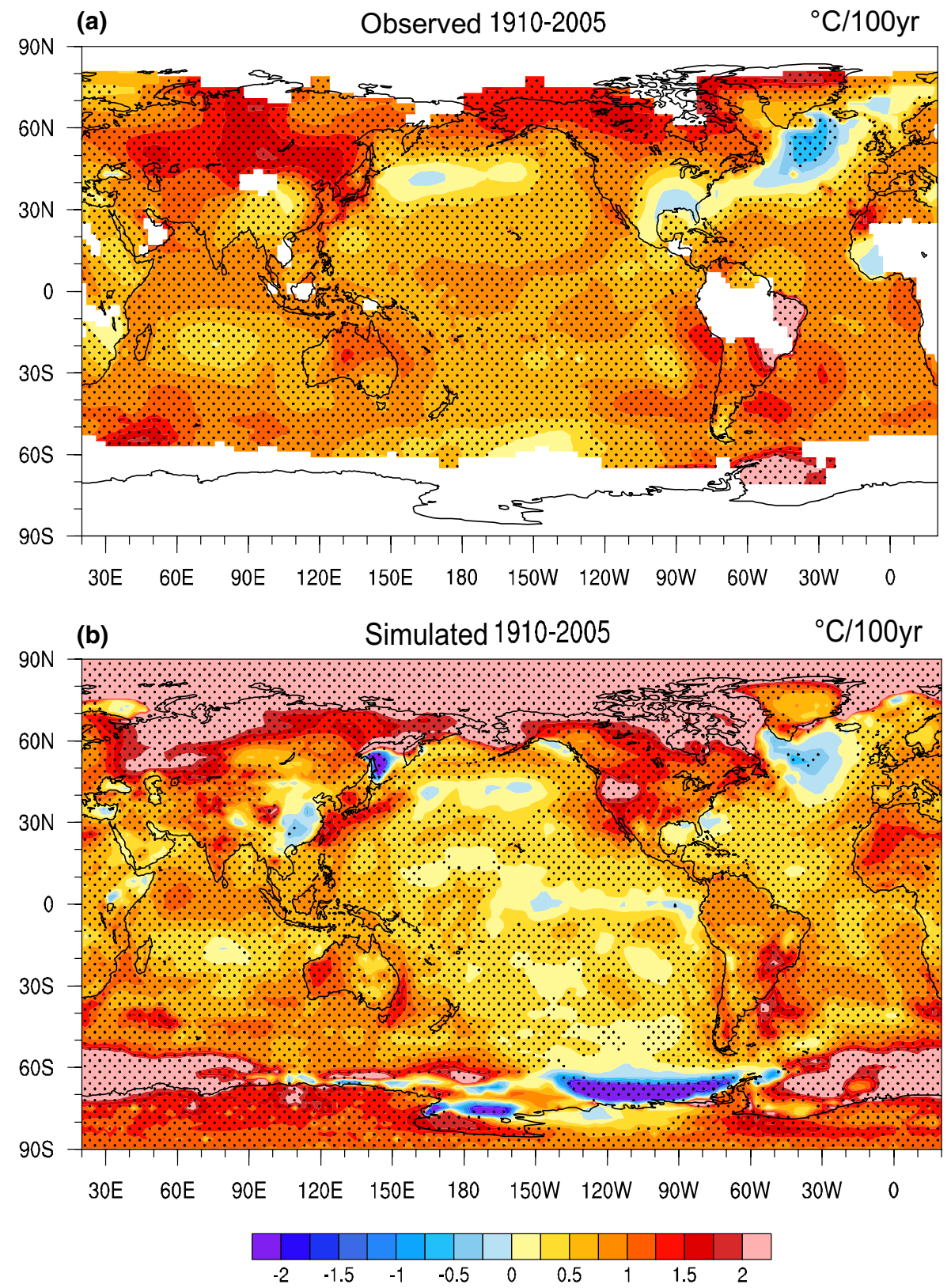

obvious multidecadal variability. Moreover, this multidecadal variability is also found in the $\mathrm{NH}$ and $\mathrm{SH}$ (Fig. 6). It is clear that the rates of SAT (LSAT) increase in the NH over the periods $1910-1945\left[+0.178(+0.152)^{\circ} \mathrm{C} \mathrm{decade}^{-1}\right]$ and $1975-1998\left[+0.242(+0.310){ }^{\circ} \mathrm{C}\right.$ decade $\left.^{-1}\right]$ are noticeably higher than the GMST (LSAT) trends for the same periods $\left[+0.137(+0.128)\right.$ and $+0.187(+0.279){ }^{\circ} \mathrm{C}$ decade $^{-1}$, respectively], whereas the rates of SAT increase in $\mathrm{SH}$ are $+0.091(+0.059)$ and $+0.131(+0.210){ }^{\circ} \mathrm{C}$ decade $^{-1}$ respectively, which are lower than the GMST (LSAT) trends for the same periods (similar to that shown in the model) (Fig. 6a). This result indicates that the increase of NH SAT enhances the GMST (LSAT) change, whereas that of the
SH considerably limits the increase in GMST (LSAT). This contrast can be interpreted as a response to the different distributions of ocean and land across the $\mathrm{NH}$ and SH. The oceans store huge amounts of heat, and oceanic processes are much slower than those on land; therefore, the warming rate of the $\mathrm{SH}$ is much slower than that of the $\mathrm{NH}$.

For 1940-1975, consistent with observation and simulation, the $\mathrm{NH}\left(-0.059{ }^{\circ} \mathrm{C}\right.$ decade $\left.^{-1}\right)$ follows the global trend $\left(-0.021{ }^{\circ} \mathrm{C}\right.$ decade $\left.{ }^{-1}\right)$, whereas the SH shows a slight warming trend $\left(+0.02{ }^{\circ} \mathrm{C}\right.$ decade $\left.^{-1}\right)$. The model simulation of the hemispheric trends show the same characteristics as the observations during the first three periods (Fig. 6). During the most recent hiatus period (2001-2013), the 
(a)

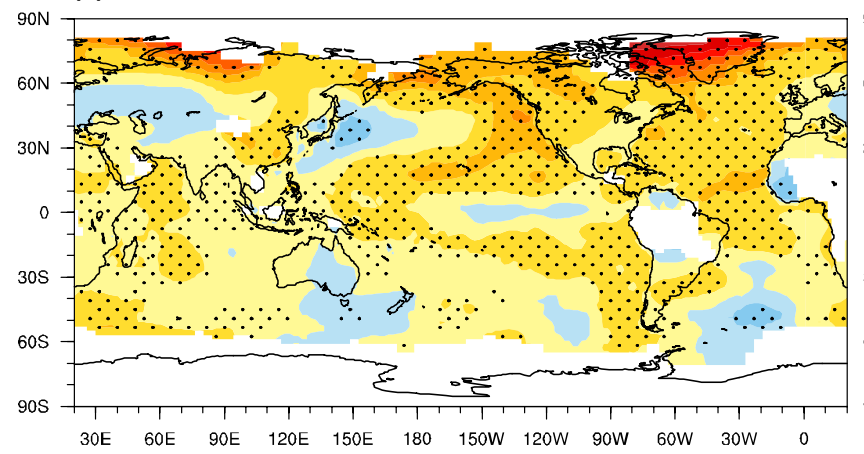

(c)

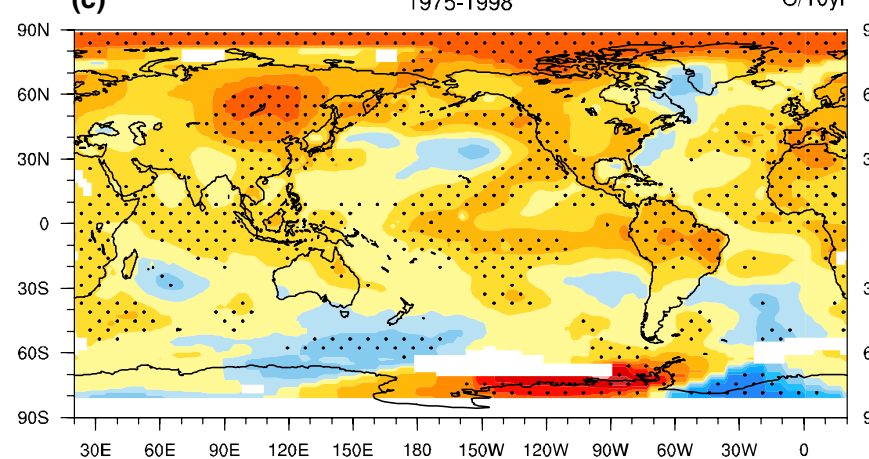

(b)

1940-1975

${ }^{\circ} \mathrm{C} / 10 \mathrm{yr}$

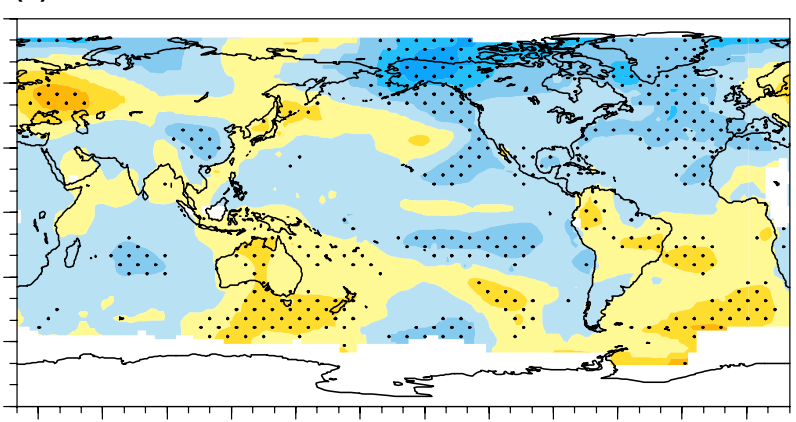

$30 \mathrm{E} \quad 60 \mathrm{E} \quad 90 \mathrm{E}$ 120E $150 \mathrm{E}$ 180 150W 120W 90W 60W $30 \mathrm{~W}$ -

(d) 2001-2013

${ }^{\circ} \mathrm{C} / 10 \mathrm{yr}$

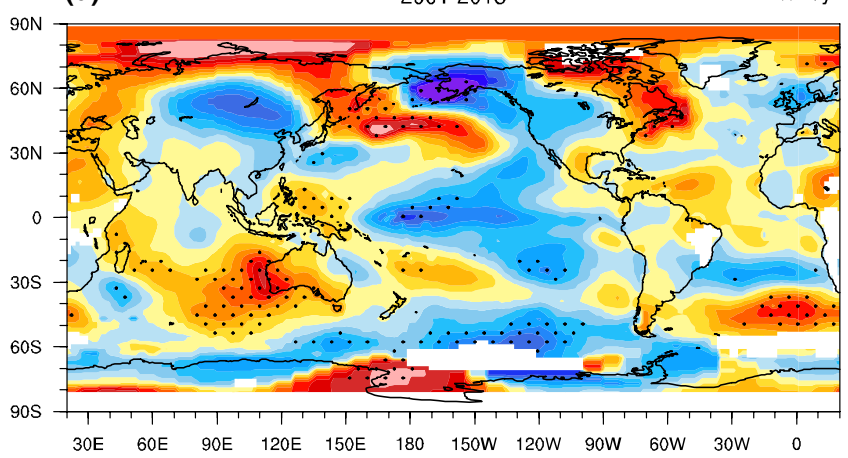

${ }^{\circ} \mathrm{C} / 10 \mathrm{yr}$
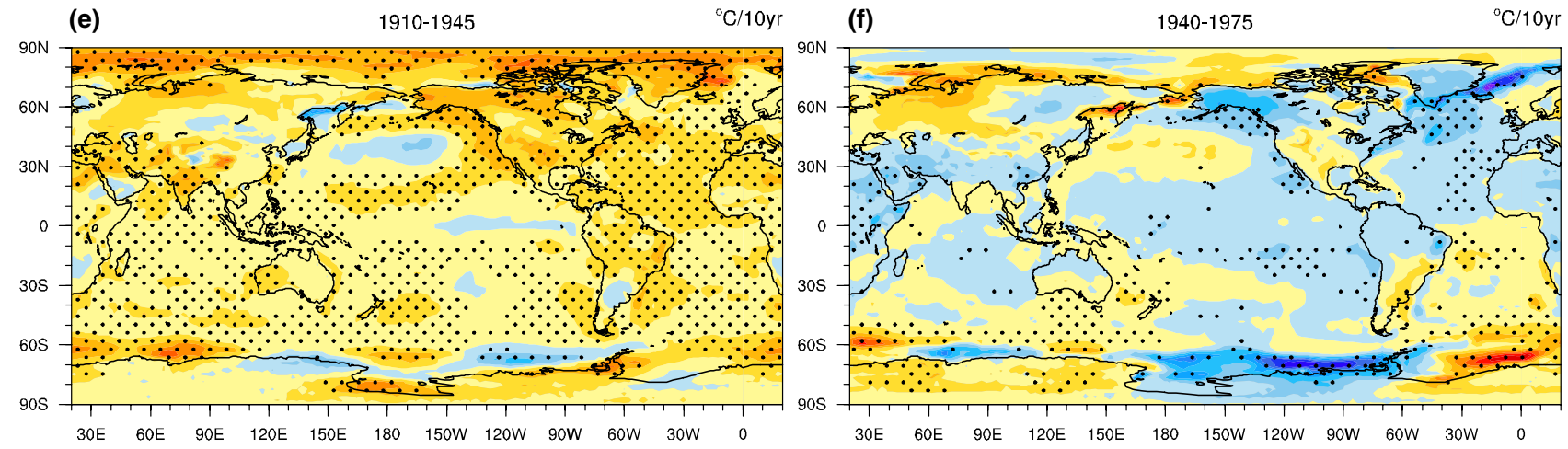

(g)

$1975-1998$

${ }^{\circ} \mathrm{C} / 10 \mathrm{yr}$

(h) $2001-2013$

${ }^{\circ} \mathrm{C} / 10 \mathrm{yr}$
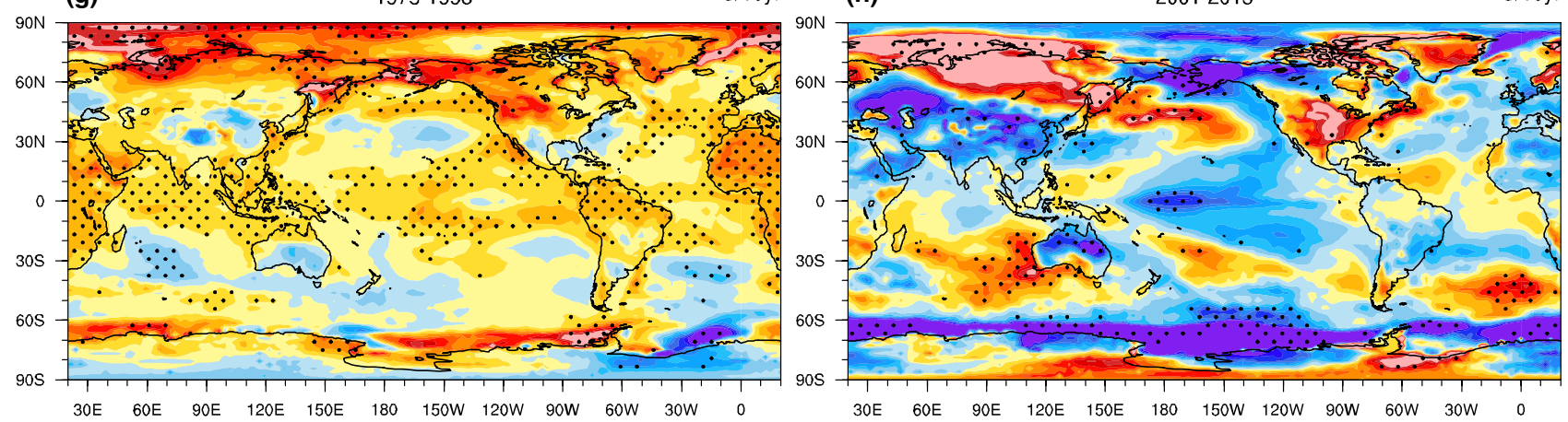

$30 \mathrm{E} \quad 60 \mathrm{E} \quad 90 \mathrm{E} \quad 120 \mathrm{E} \quad 150 \mathrm{E} \quad 180$ 150W $120 \mathrm{~W}$ 90W $60 \mathrm{~W}$ 30W 0

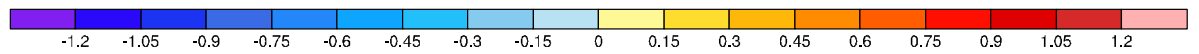

Fig. 5 Observed and simulated GMST trends during different periods. Observed GMST trends for a 1910-1945, b 1940-1975, c 19751998, and d 2001-2013; and CESM_CAM5.3 simulated GMST trends for e 1910-1945, f 1940-1975, g 1975-1998, and h 2001-
2013. Units: ${ }^{\circ} \mathrm{C}$ decade ${ }^{-1}$. Shading indicates GMST trends for each decade. Stippling indicates regions exceeding the 95\% confidence level (two-tailed Student's $t$ test). White areas indicate missing values 
Table 1 Observed and simulated percentage of spatial sign consistency for the entire globe and land areas only for alternating periods of rapid warming and slight cooling (1910-1945, 1940-1975, 19751998, and 2001-2013)

\begin{tabular}{lllll}
\hline & $1910-1945$ & $1940-1975$ & $1975-1998$ & $2001-2013$ \\
\hline Global (\%) & 78.0 & 62.6 & 85.8 & 59.8 \\
Land (\%) & 76.7 & 60.9 & 84.1 & 50.5 \\
\hline
\end{tabular}

observation shows a GMST trend of $+0.039{ }^{\circ} \mathrm{C}$ decade $^{-1}$, whereas the simulation shows $-0.029^{\circ} \mathrm{C} \mathrm{decade}^{-1}$, but neither are statistically significant. The discrepancy between the observations and the model is probably caused by the Arctic amplification (Cohen et al. 2012), which strengthens cooling over Eurasia and Australia and is not incorporated into the simulation.

The rate of GMST and LSAT increase is clearly much higher in the later period than the earlier period for both warming and cooling periods (Fig. 6a, b). Taking the 1975-1998 observed NH SAT variation as an example, it increases by about $36 \%$ (61.6\% in simulation) compared with the first period of faster warming (Fig. 6a). The GMST multidecadal average follows a gradually increasing trend over the period 1910-2013.

To quantitatively analyze the contribution of $\mathrm{NH}$ and SH to GMST and LSAT multidecadal trends, we compute the contribution rates of the NH and SH SAT variability to the GMST trend (Fig. 7). The observed contribution rates of the NH SAT variability to the GMST trend are $70.8 \%$ (1910-1945) and 67.6\% (1975-1998) respectively during the two warming periods, which are over two times higher than those for the SH ( $29.2 \%$ and $32.4 \%$, respectively). The simulated results also show that the NH SAT variabilities

(a)

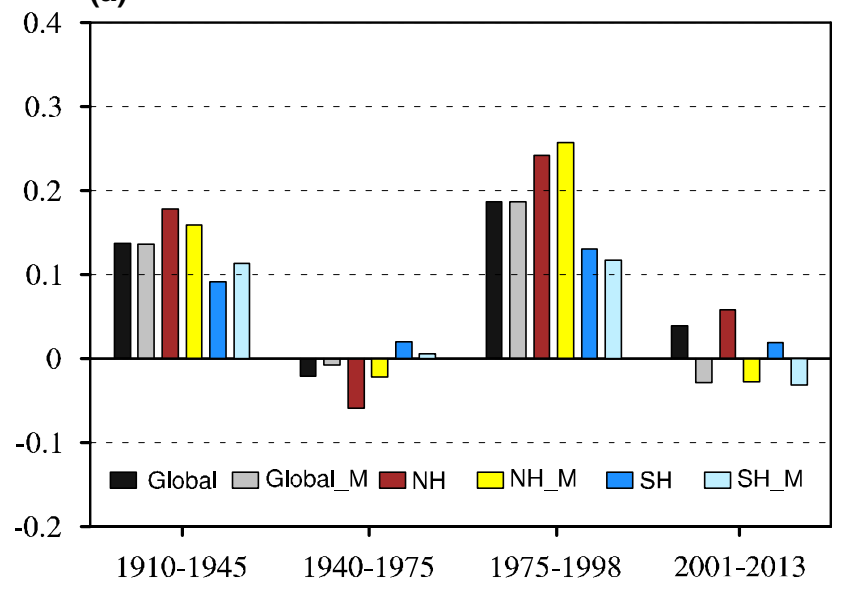

Fig. 6 Observed and simulated multi-decadal SAT trends in four different periods. GMST (left), LSAT (right). Black, grey, brown, yellow, royal blue, and pale blue bars denote SAT trends of the observed contribution to GMST (58.5\% and $68.7 \%$ for $1910-1945$ and 1975-1998 respectively) during warming periods are much higher than those of the SH $(41.5 \%$ and $31.3 \%$ for 1910-1945 and 1975-1998 respectively) (Fig. 7a). The same can be seen in LSAT for observation and model simulation results (Fig. 7b).

Between 1940 and 1975, the SH SAT multidecadal change makes a contribution to global rapid warming of $-33.5 \%$, based on the observations $(-34.8 \%$ in the model simulation), which is opposite to the NH SAT multidecadal change contribution to GMST multidecadal change $(+133.5 \%$ for the observation and $+134.8 \%$ for the model simulation) (Fig. 7a). As for the changes in LSAT during this period, the proportion accounted for by the NH SAT variability contribution rate to LSAT multidecadal trend is also similar to GMST (131.5\% for the observation and $164.3 \%$ for the model simulation), which is much greater than that from the SH $(-31.5 \%$ for the observation and $-64.3 \%$ for the model simulation) (Fig. 7b). These findings indicate that NH SAT multidecadal variability contributes more than SH SAT multidecadal variability to the GMST and LSAT multidecadal trends. The NH SAT multidecadal variability is the main reason for GMST and LSAT cooling during 1940-1975 and the SAT change over the SH acts to offset this cooling effect. The contribution rate of NH SAT variability to the GMST multidecadal trend over the period 2001-2013 is $77.3 \%$, which is higher than that of SH (22.7\%). However, the contribution rate of SH SAT variability to the LSAT trend (54.4\%) is higher than that of $\mathrm{NH}(45.6 \%)$. This corresponds with the $\mathrm{SH}$ land warming more quickly $\left(+0.098^{\circ} \mathrm{C}\right.$ decade $\left.^{-1}\right)$ than the $\mathrm{NH}$ land $(+$ $0.042{ }^{\circ} \mathrm{C}$ decade $^{-1}$ ) and the SH land have a homogeneous spatial warming pattern (Fig. $5 \mathrm{~d}, \mathrm{~h}$ ). This indicates that $\mathrm{SH}$ (b)

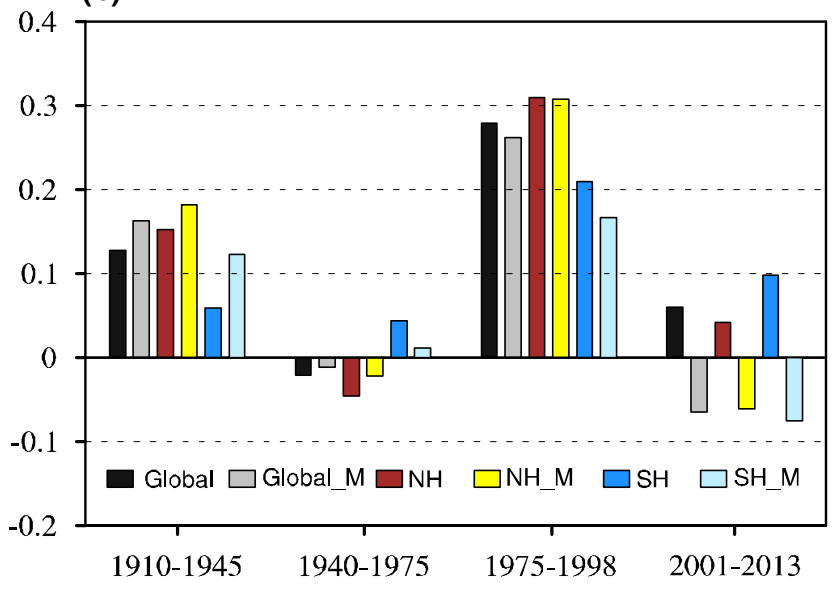

global, model simulated global, observed $\mathrm{NH}$, simulated $\mathrm{NH}$, observed $\mathrm{SH}$, and simulated $\mathrm{SH}$, respectively 
(a)

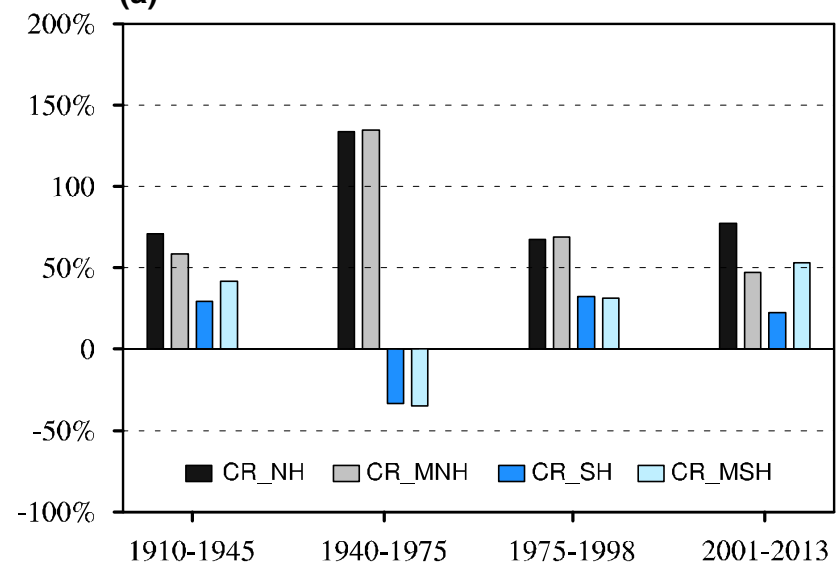

(b)

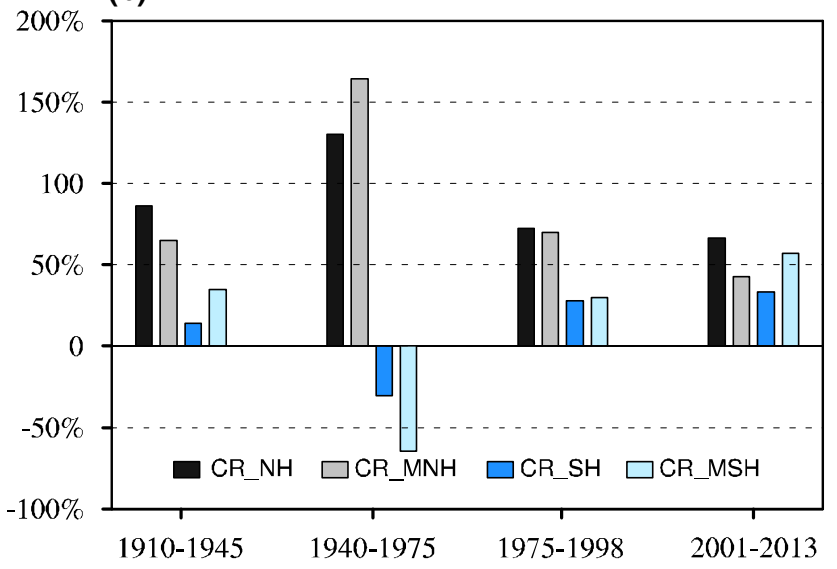

Fig. 7 As in Fig. 6, but for the contribution rates. Black, grey, royal blue, and pale blue bars indicate contribution rates for the observed NH, simulated $\mathrm{NH}$, observed $\mathrm{SH}$, and simulated $\mathrm{SH}$, respectively

LSAT variability has important impacts on modulating the global LSAT trend during 2001-2013.

The above results indicate that although the $\mathrm{NH}$ and the SH SAT multidecadal variabilities both make positive contributions to the GMST multidecadal trend during the different periods (except for 1940-1975), their contributions are not identical. Moreover, the NH SAT contribute to the GMST and LSAT multidecadal trend more than SH SAT does during the four periods between 1910 and 2013, except for the contribution rate to LSAT between 2001 and 2013. The GMST (LSAT) shows a weak cooling trend driven mainly by the NH between 1940 and 1975 .

\subsection{Contribution of regional SST changes to the GMST (LSAT) multidecadal variability}

To further illustrate the effects of regional SST changes on the GMST (LSAT) trend, we conduct six individual ocean SST forcing experiments (sensitivity experiments) and evaluate the contribution of each experiment to the GMST (LSAT) trend. We calculate the sign consistency rate between the combined six individual ocean region SST forcing simulations and the entire global SST forcing simulation to illustrate the similarity of LSAT spatial pattern, and the results are $86.6 \%, 77.9 \%, 74.8 \%, 60.3 \%$ for 1910-1945, 1940-1975, 1975-1998, 2001-2013 respectively (not shown). This indicated that the combined six individual ocean SST forcing experiments can reproduce the majority of the LSAT multidecadal trend driven by the entire global SST variation, in spite of some discrepancies exist on amplitude between them. The trend and contribution of each SST forcing experiment to the different periods' GMST trend are listed in Table 2, and the contribution rate of each SST forcing experiment to the different periods' GMST and LSAT trends are presented in Fig. 8.
When considering contribution from different periods, we find that over the periods 1910-1945 and 1975-1998, the GMST (LSAT) trends simulated by the individual ocean SST forcing experiments all contribute to the GMST (LSAT) rapid warming trend, as indicated in the global SST forcing experiment (Fig. 8a, b). The contribution of different SST forcing experiments to the GMST and LSAT varies. The experiments show that the contribution rates of SST variation in SO (30.1\%), NA (27.5\%), and WP (24.3\%) to the GMST are higher than those in the other SST forcing experiments over 1910-1945 period. As for 1975-1998, the contribution rates of SST variation in IO (39.7\%), NA (38.6\%), WP (37.5\%), and TP (36.8\%) to the GMST are much higher than those of SO (13.4\%) and NP (20.5\%) (Fig. 8a).

In the 1940-1975 and 2001-2013 cooling periods, the SAT trends generated by the individual ocean SST forcing experiments do not always have a positive contribution to the GMST (LSAT) trend from the global SST forcing experiment; only a few individual ocean SST forcing simulation results are in phase with the GMST (LSAT) trend (Fig. 8a, b). For 1940-1975, the individual ocean SST forcing experiments show a wide range of GMST trends and contribution rates. Only IO $\left(-0.01^{\circ} \mathrm{C}\right.$ decade $\left.^{-1}\right)$, NA $\left(-0.008{ }^{\circ} \mathrm{C} \mathrm{decade}{ }^{-1}\right)$, and WP $\left(-0.006{ }^{\circ} \mathrm{C}\right.$ decade $\left.^{-1}\right)$ capture the cooling trend seen in the global SST forcing experiment $\left(-0.008{ }^{\circ} \mathrm{C}\right.$ decade $\left.^{-1}\right)$ (Table 2$)$. The contribution rates of these three ocean areas to the GMST trend are $128.4 \%, 102.1 \%$, and $73 \%$, respectively. The other experiments fail to capture the weak cooling trend during this period (Fig. 8a). The same results can be found for LSAT (Fig. 8b). It is clear that the relative contribution rates of SAT variation over IO and NA to the GMST trend both exceed $100 \%$, which is because SST changes over IO and NA drove the GMST cooling effect and offset the warming simulated in other experiments during 1940-1975 (i.e., 
Table 2 SAT trends $\left({ }^{\circ} \mathrm{C}\right.$ decade $^{-1}$ ) and relative contributions of global and individual ocean SST forcing over the periods $1910-1945$, 1940-1975, 1975-1998, and 2001-2013

\begin{tabular}{lllll}
\hline & $1910-1945$ & $1940-1975$ & $1975-1998$ & $2001-2013$ \\
\hline Global ocean & $0.136^{* *}$ & $-8.1 \times 10^{-3}$ & $0.187 * *$ & $-2.92 \times 10^{-2}$ \\
NP & $2.67 \times 10^{-2 * *}$ & $7.58 \times 10^{-3}$ & $3.84 \times 10^{-2 * *}$ & $-2.25 \times 10^{-3}$ \\
& $19.6 \%$ & $-94 \%$ & $20.5 \%$ & $7.71 \%$ \\
NA & $3.74 \times 10^{-2 * *}$ & $-8.27 \times 10^{-3}$ & $7.21 \times 10^{-2 * *}$ & $5.07 \times 10^{-2}$ \\
& $27.5 \%$ & $102.1 \%$ & $38.6 \%$ & $-173.6 \%$ \\
TP & $2.33 \times 10^{-2 * *}$ & $2.91 \times 10^{-3}$ & $6.89 \times 10^{-2 * *}$ & $-2.14 \times 10^{-2}$ \\
& $17.1 \%$ & $-35.9 \%$ & $36.8 \%$ & $73.3 \%$ \\
WP & $3.31 \times 10^{-2 * *}$ & $-5.91 \times 10^{-3}$ & $7.02 \times 10^{-2 * *}$ & $1.02 \times 10^{-3}$ \\
& $24.3 \%$ & $73.0 \%$ & $37.5 \%$ & $-3.49 \%$ \\
IO & $2.93 \times 10^{-2 * *}$ & $-1.04 \times 10^{-2 *}$ & $7.42 \times 10^{-2 * *}$ & $8.31 \times 10^{-2 * *}$ \\
& $21.5 \%$ & $128.4 \%$ & $39.7 \%$ & $-284.6 \%$ \\
SO & $4.10 \times 10^{-2 * *}$ & $1.37 \times 10^{-2 * *}$ & $2.50 \times 10^{-2 * *}$ & $6.66 \times 10^{-2}$ \\
& $30.1 \%$ & $-169.1 \%$ & $13.4 \%$ & $-228.1 \%$ \\
\hline
\end{tabular}

Positive and negative contribution rates are shown. The least-squares method is used to estimate trends. A single asterisk (*) indicates trends significant at the $90 \%$ level, and a double asterisk (**) indicates trends significant at the 95\% level (Student's $t$ test)
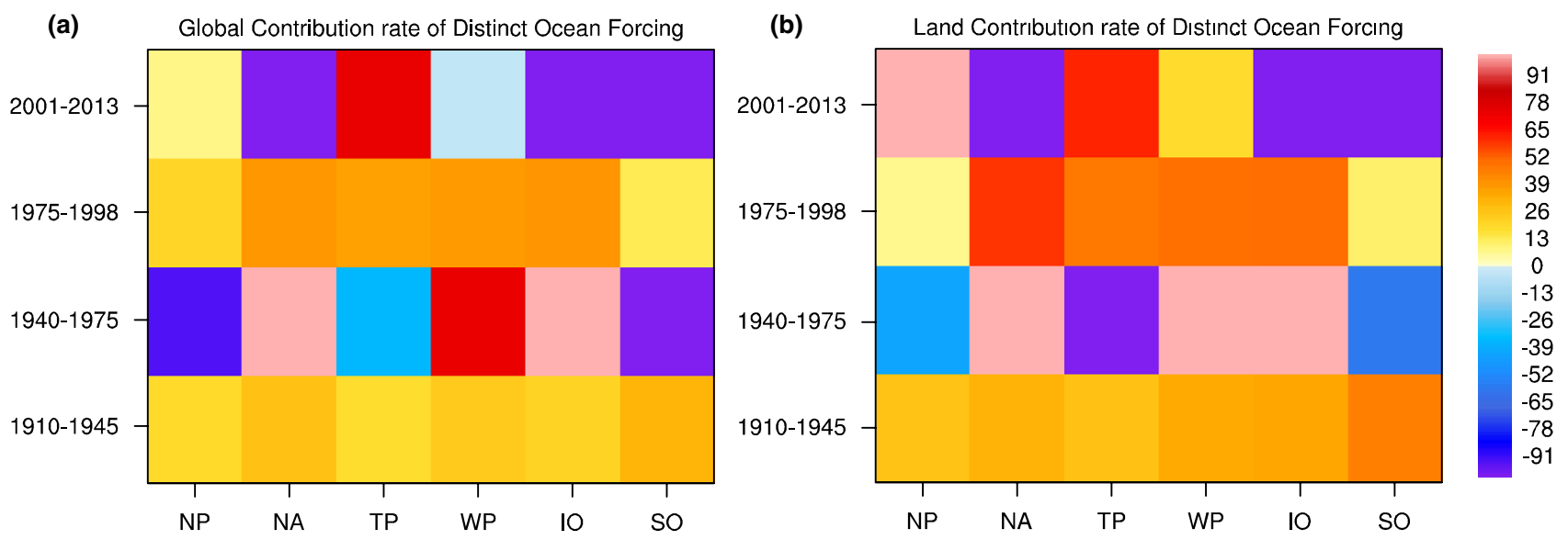

Fig. 8 Relative contribution rates of individual ocean SST forcing to the a GMST, and b LSAT trends over the periods 1910-1945, 1940-1975, 1975-1998, and 2001-2013

the SAT multidecadal trends of IO and NA are greater than that of the global SST forcing experiment). During the period 2001-2013, only TP and NP contribute to the GMST trend, at $73.3 \%$ and $7.71 \%$ respectively (Fig. 8a). The same results are found for LSAT, except that WP makes a positive contribution to LSAT, opposite to the negative contribution that it makes to GMST (Fig. 8b).

The above findings indicate that each ocean SST change can have a positive contribution to the GMST (LSAT) over the periods 1910-1945 and 1975-1998. As for the periods 1940-1975 and 2001-2013, only partial ocean SST forcing can positively modify the cooling temperature trend as indicated by GMST (LSAT), whereas other regions have negative effects on the GMST (LSAT) multidecadal cooling trend.
The individual ocean SST forcing experiments reveal that the various SST forcing experiments do not always have the same impact on the GMST and LSAT multidecadal trend during the four periods. The SAT response in SO makes the largest contribution to the GMST trend between 1910 and 1945. However, over the period 1975-1998, the contribution rate of SO (13.4\%) to the GMST multidecadal trend is smaller than the results from the other individual ocean SST forcing experiments (Table 2; Fig. 8). The average contribution rate of the individual ocean SST forcing experiments over $1975-1998$ is $31.08 \%$, which is twice above the SO's contribution rate. During the cooling periods of 1940-1975 and 2001-2013, SST variation in SO even makes a negative contribution to the GMST multidecadal trend. Indian Ocean SST change only contribute $21.5 \%$ to 
GMST multidecadal trend during 1910-1945, and makes the most important contribution to the GMST trend during the periods of 1940-1975 (128.4\%) and 1975-1998 (39.7\%), compared with the other experiments. As for 2001-2013, IO makes a negative contribution to the GMST multidecadal trend. It is clear that NA and WP have important effects on GMST multidecadal trend throughout the 20th century. Eastern tropical Pacific SST change affect the GMST trend during the recent hiatus period (2001-2013) and contribute 73.3\% of the GMST trend along with NP (7.71\%) (Fig. 8).

The above results indicate that SST change in different oceans have varying effects on the GMST multidecadal trend. NA and WP make explicit contributions to the whole 20th century GMST multidecadal trend, which reveals that changes in the SST of NA and WP are important controls on the decadal variability of the GMST throughout the 20th century. The SO makes the greatest contribution to the 1910-1945 warming period, but its contribution to the GMST trend is low during the other three periods. The IO makes the greatest contribution to modulating the GMST trend between 1940 and 1975 and 1975-1998.

\subsection{Multidecadal continental SAT trends tied to SST changes}

The SST change in different oceans also have varying effects on different continents. As mentioned in Sect. 4.2, SST variations in SO, NA, and WP have higher contributions to the GMST multidecadal trend than other SST forcing experiments between 1910 and 1945. Therefore, it is also very important for us to further investigate their continental SAT responses. The multidecadal SAT trend for the Europe region from the SO $\left(+0.233{ }^{\circ} \mathrm{C}\right.$ decade $\left.^{-1}\right)$ is higher than that from the global SST forcing experiment $\left(+0.163{ }^{\circ} \mathrm{C}\right.$ decade $^{-1}$ ). In addition, the contribution rates of Europe SAT variability in SO to GMST is $142.9 \%$. This indicates that the high contribution rate from SO to global SST forcing experiment SAT multidecadal trend is closely related to the overestimate of the multidecadal SAT trend for Europe (Figs. 9h, 13a). We can also conclude that the SAT multidecadal trend in NA is consistent with the global SST forcing experiment SAT multidecadal trend for Asia (56.2\%), South America (52.2\%), and Africa (73.2\%) during this period (Figs. 9d, 13a). The WP SST variation explain the multidecadal SAT trend for most continents, except for a negative contribution for Europe $(-24.1 \%)$ and weak positive contribution for South America (3.5\%) (Figs. 9f, 13a). As for the spatial pattern, the WP SST variation explain the north of $60^{\circ} \mathrm{N}$ SAT trend very well (Fig. 9f). The SST variations in IO, NP, and $\mathrm{TP}$ also have different contributions to the continental SAT multidecadal trends. SST variations in IO contributes the most to the Europe SAT multidecadal change (72.4\%), NP contributes the most to the North America SAT multidecadal change (85.5\%), and contributions of TP to different continents are all positive (Figs. 9c, e, g; 13a). Between 1975 and 1998, SST variation in IO, NA, and WP have an excellent performance in explaining the SAT trends across Asia, North America, and South America, with contribution rates all above $31.3 \%$ (Figs. 10d, f, g; 13b). The SST variation in NA and IO also make clear positive contributions to the European SAT trend, with relative contribution rates of $134.9 \%$ and $101.5 \%$, respectively (Figs. 10d, g; 13b). However, SST variations in WP contributes only $11.3 \%$ to this region during this period (Figs. 10f, 13b). The above findings demonstrate that even though individual ocean SST forcing experiments all make positive contributions to the GMST trend during the period of accelerated warming, different regions' SST still have varying impacts on continental SAT multidecadal changes during warming periods. For a certain ocean, discrepancies would also occur for different continents.

As for 1940-1975, SST variation in IO makes a positive contribution to Asia, North America, Africa, and Australia (Figs. 11g, 13c), which differs markedly to the situation for the periods 1910-1945 and 1975-1998. SST variations in NA contributes to the SAT trends across Asia, South America, and Africa, and WP contributes to all continents except for South America during this period (Figs. 11d, 13c). TP captures the SAT trends of Asia, South America, Africa, and Australia during the period 2001-2013 better than the other SST forcing experiments (Figs. 12e, 13d). There is no doubt that the change in TP SST play a key role in modulating the GMST trend during the recent hiatus period. These results indicate that SST changes in the various oceans do not always play the same role in modifying GMST variability during the four periods.

The SST variations in NA, TP, WP, and IO simulate the Asia SAT trend well during the whole 20th century, which implies that the SAT multidecadal trend in Asia has great relevance with SST variation of these oceans (Fig. 13). It is also clear that NP simulates the spatial pattern of North America well during the whole 20th century (Figs. 9c, 10c, 11c). Despite some differences between the global SST forcing simulations and observations, the North American SAT trend from the NP SST forcing remains consistent with the observations during the period 2001-2013 (Fig. 12c). The relative contribution rates of the individual ocean SST forcing experiments show that the SAT trends of the NH continents are more consistent with the global SST forcing experiment trend in both the accelerated and slower warming periods, compared with the SH continents (Fig. 13). The above result indicates that the SST forcing experiments during the different periods do not always have the same impacts on the multidecadal SAT trends of the various continents. The temporal and spatial variations show no periodic variation in the multidecadal regional SAT trend. 
(a) Observed

1910-1945

${ }^{\circ} \mathrm{C} / 10 y \mathrm{r}$

(b) Total Simulated

1910-1945

${ }^{\circ} \mathrm{C} / 10 \mathrm{yr}$
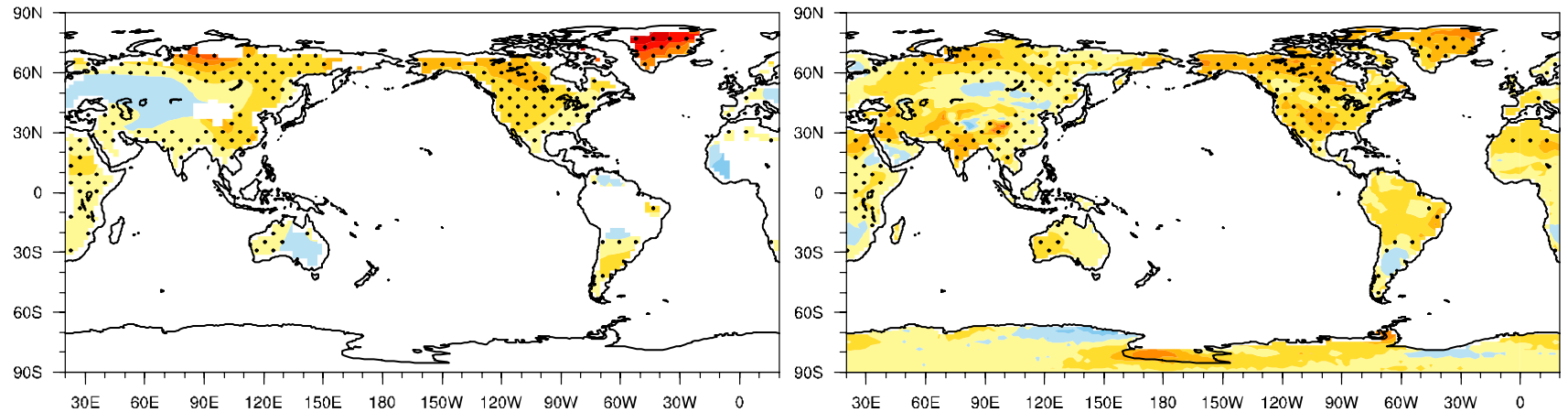

(c) NPreal

1910-1945

${ }^{\circ} \mathrm{C} / 10 \mathrm{yr}$

(d) NAreal

1910-1945

${ }^{\circ} \mathrm{C} / 10 \mathrm{yr}$
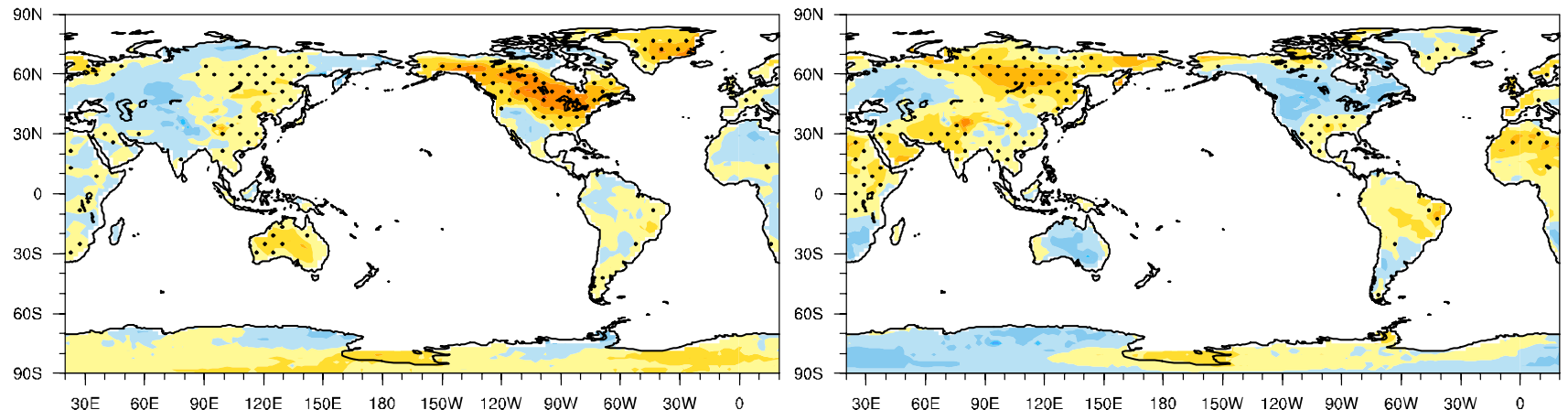

(e) TPreal

1910-1945

${ }^{\circ} \mathrm{C} / 10 \mathrm{yr}$

(f) WPreal

1910-1945

${ }^{\circ} \mathrm{C} / 10 \mathrm{yr}$
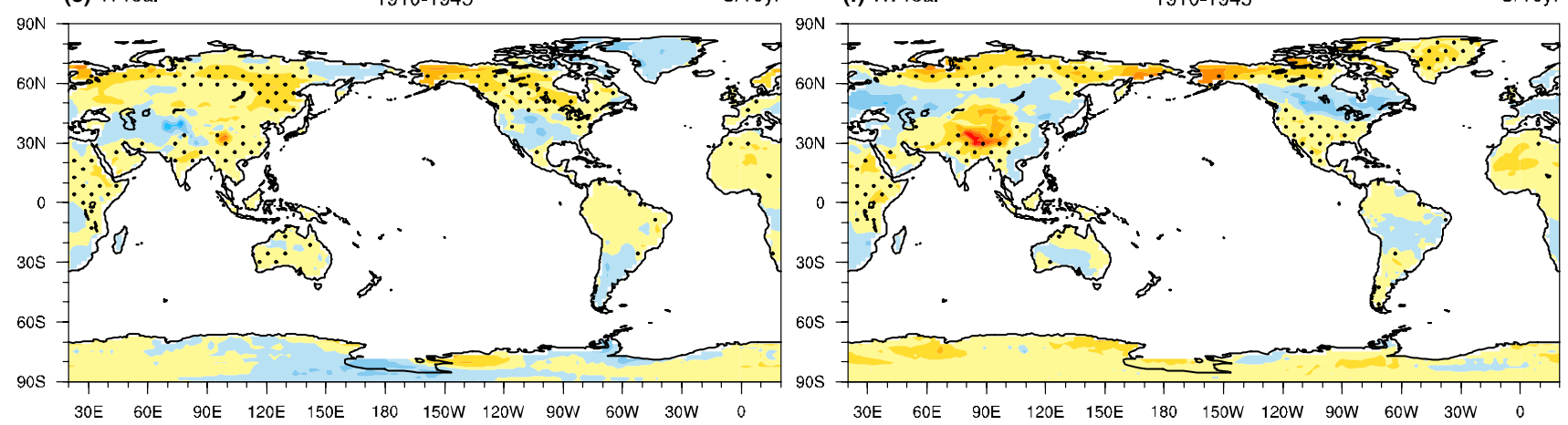

(g) IOreal

1910-1945

${ }^{\circ} \mathrm{C} / 10 y r$

(h) SOreal

1910-1945

${ }^{\circ} \mathrm{C} / 10 \mathrm{yr}$
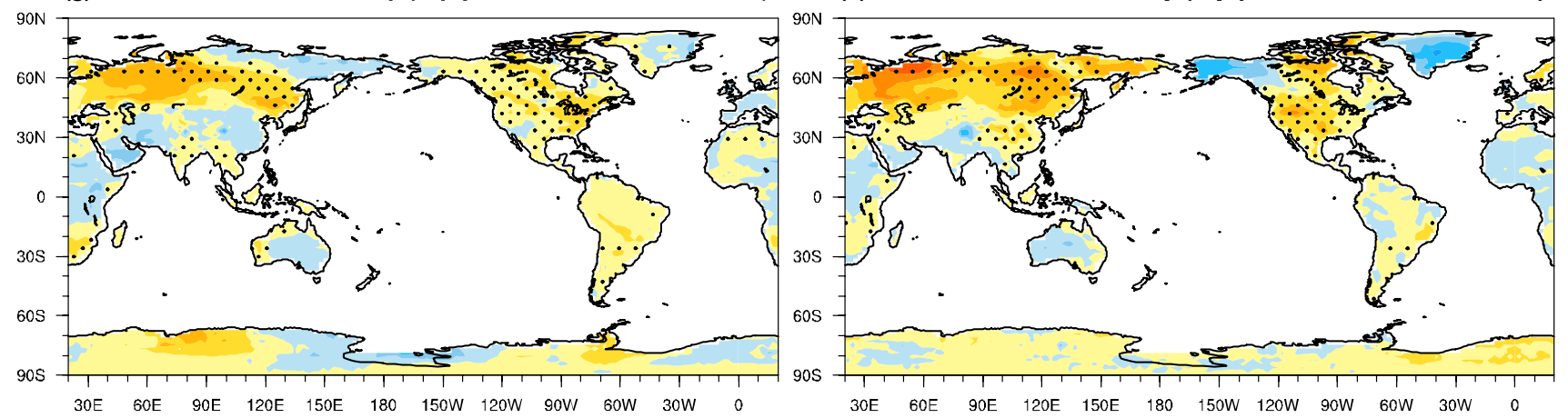

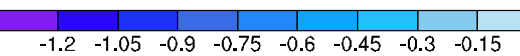

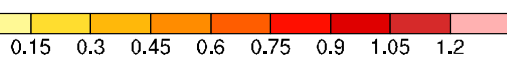

Fig. 9 LSAT trend and sign consistency of individual ocean SST forcing simulations over the period 1910-1945. Shading indicates the LSAT trend for each decade $\left({ }^{\circ} \mathrm{C}\right.$ decade $\left.^{-1}\right)$. Stippling indicates regions with the same sign trends as observations and the global SST forcing experiment 
(a) Observed

$1975-1998$

${ }^{\circ} \mathrm{C} / 10 \mathrm{yr}$

(b) Total Simulated

1975-1998

${ }^{\circ} \mathrm{C} / 10 \mathrm{yr}$
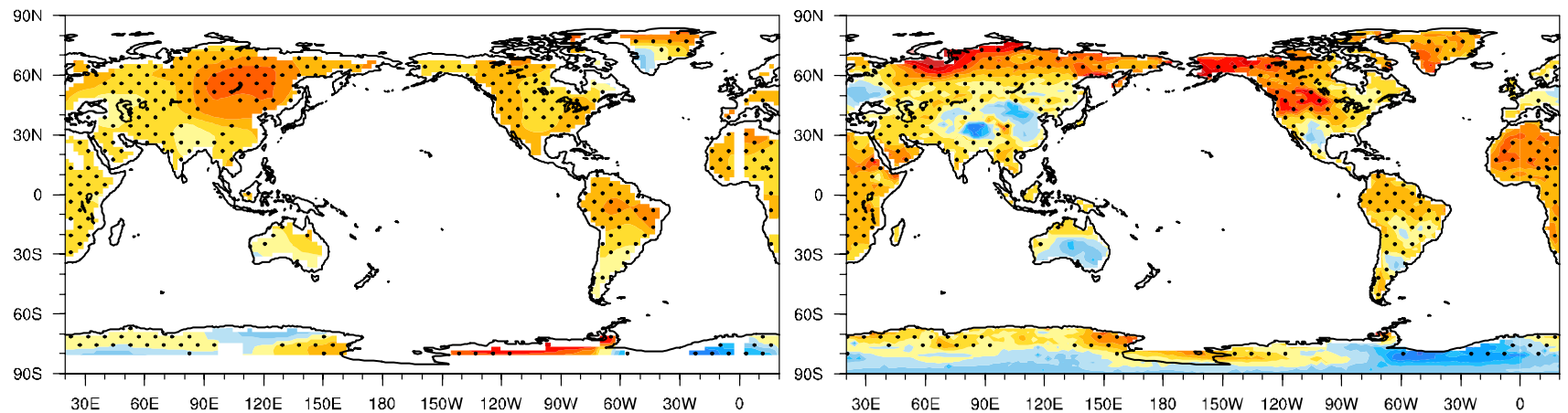

(c) NPreal

1975-1998

${ }^{\circ} \mathrm{C} / 10 \mathrm{yr}$

(d) NAreal

1975-1998

${ }^{\circ} \mathrm{C} / 10 \mathrm{yr}$
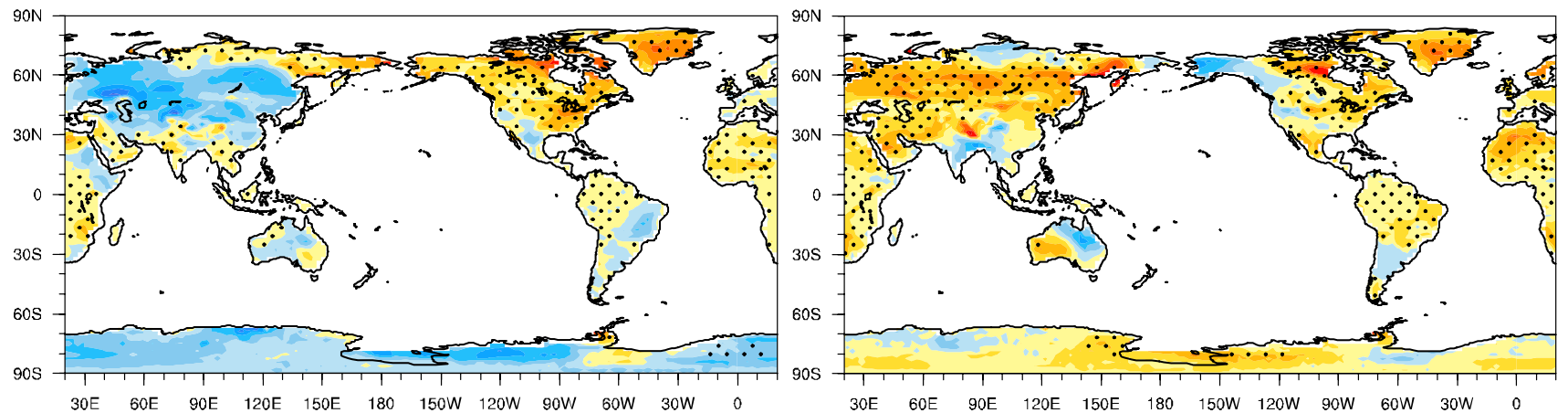

(e) TPreal

1975-1998

${ }^{\circ} \mathrm{C} / 10 \mathrm{y}$

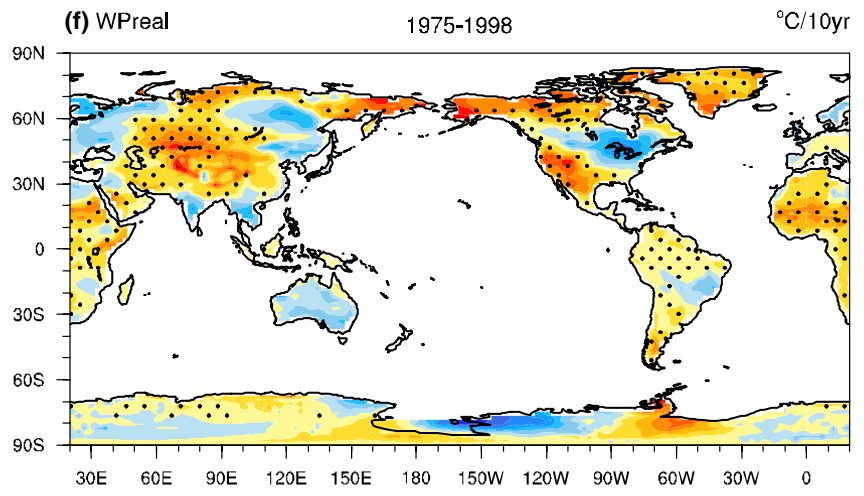

(f) WPreal

1975-1998

${ }^{\circ} \mathrm{C} / 10 \mathrm{yr}$

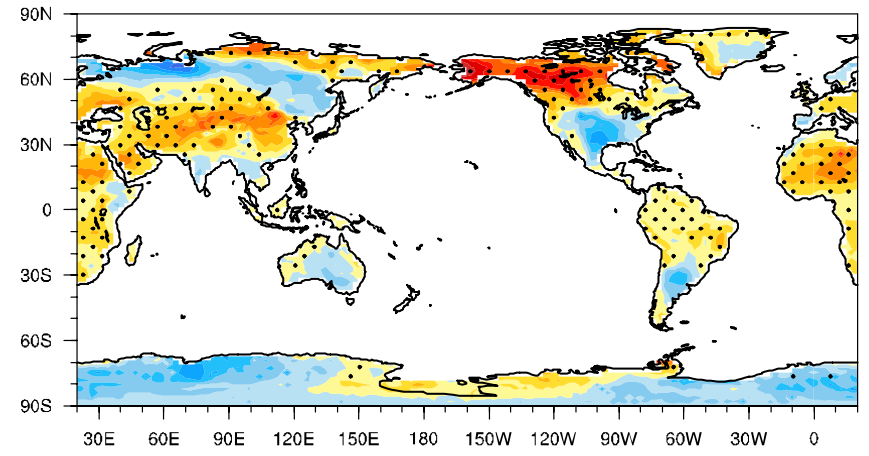

(g) |Oreal

1975-1998

${ }^{\circ} \mathrm{C} / 10 \mathrm{yr}$

(h) SOreal

1975-1998

${ }^{\circ} \mathrm{C} / 10 \mathrm{yr}$
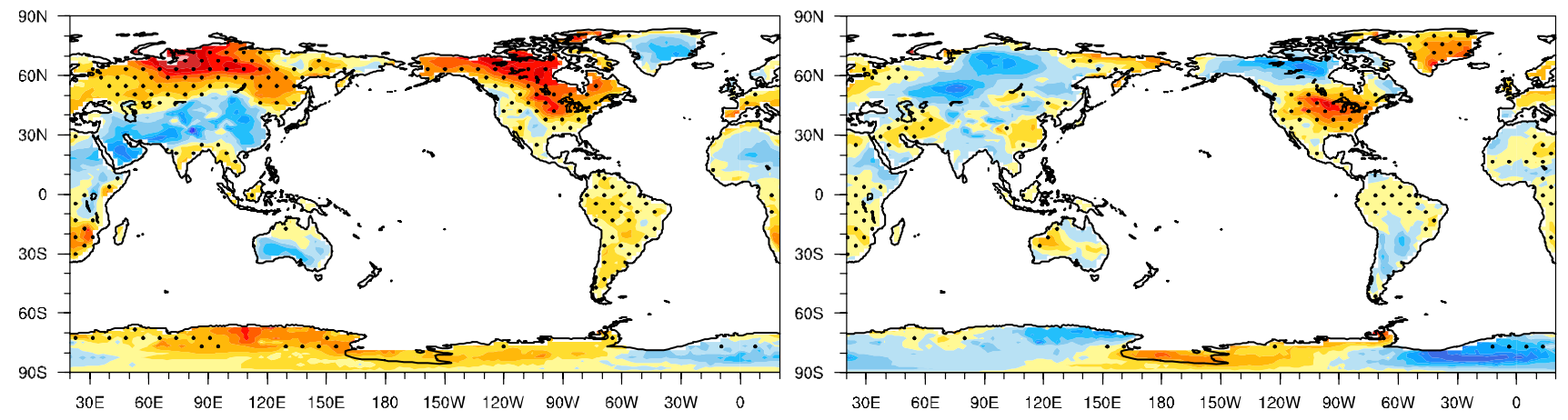

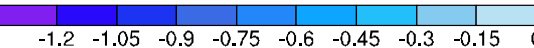

$\begin{array}{ccccccccc}\mid & \mid & \mid & \mid & & & & \\ & 15 & 0.3 & 0.45 & 0.6 & 0.75 & 0.9 & 1.05 & 1.2\end{array}$

Fig. 10 As in Fig. 9, but for 1975-1998 


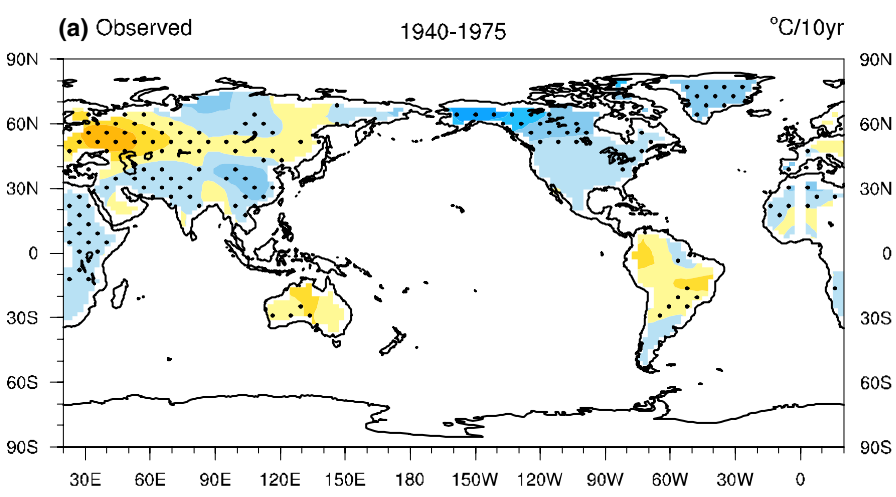

(b) Total Simulated

1940-1975

${ }^{\circ} \mathrm{C} / 10 \mathrm{yr}$

(c) NPreal

1940-1975

${ }^{\circ} \mathrm{C} / 10 \mathrm{y}$
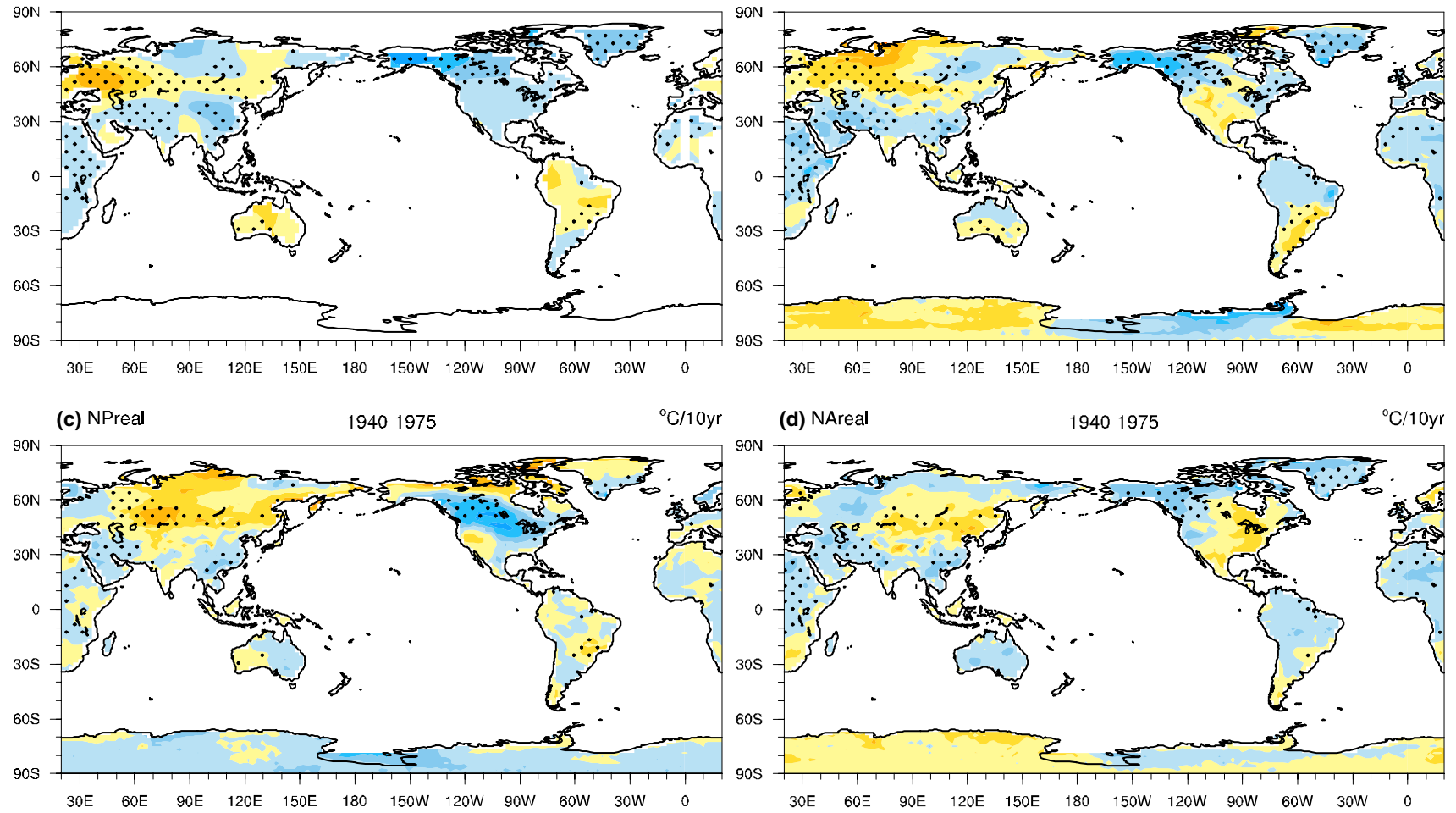

(d) NAreal

1940-1975

${ }^{\circ} \mathrm{C} / 10 \mathrm{yr}$

(e) TPreal

1940-1975

${ }^{\circ} \mathrm{C} / 10 \mathrm{yr} \quad$ (f) WPreal

${ }^{\circ} \mathrm{C} / 10 \mathrm{yr}$
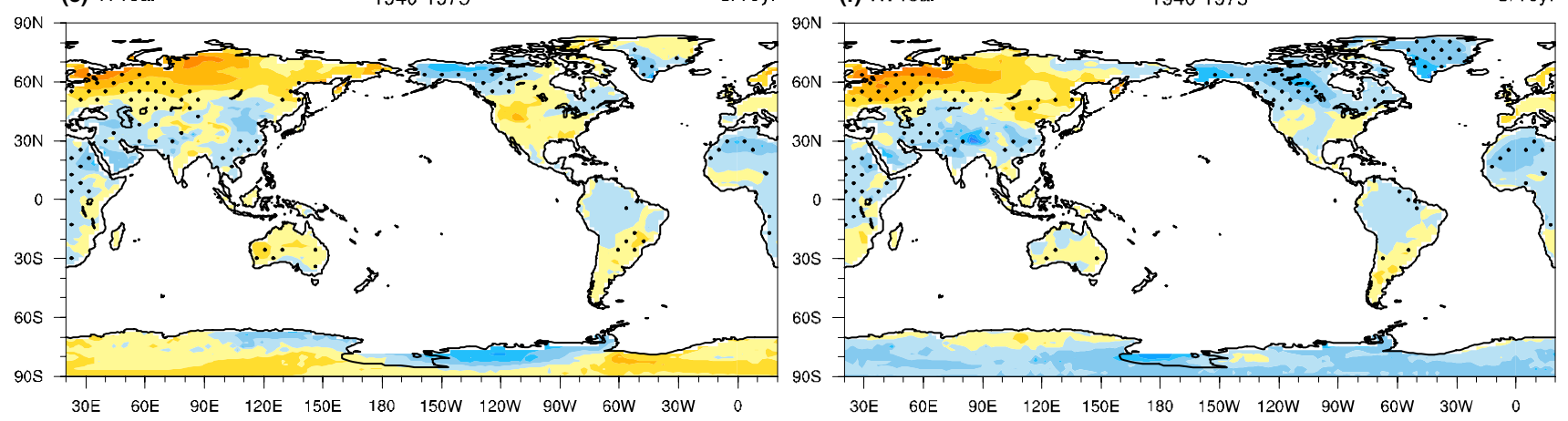

(g) IOreal

1940-1975

${ }^{\circ} \mathrm{C} / 10 \mathrm{yr}$

(h) SOreal

1940-1975

${ }^{\circ} \mathrm{C} / 10 \mathrm{yr}$
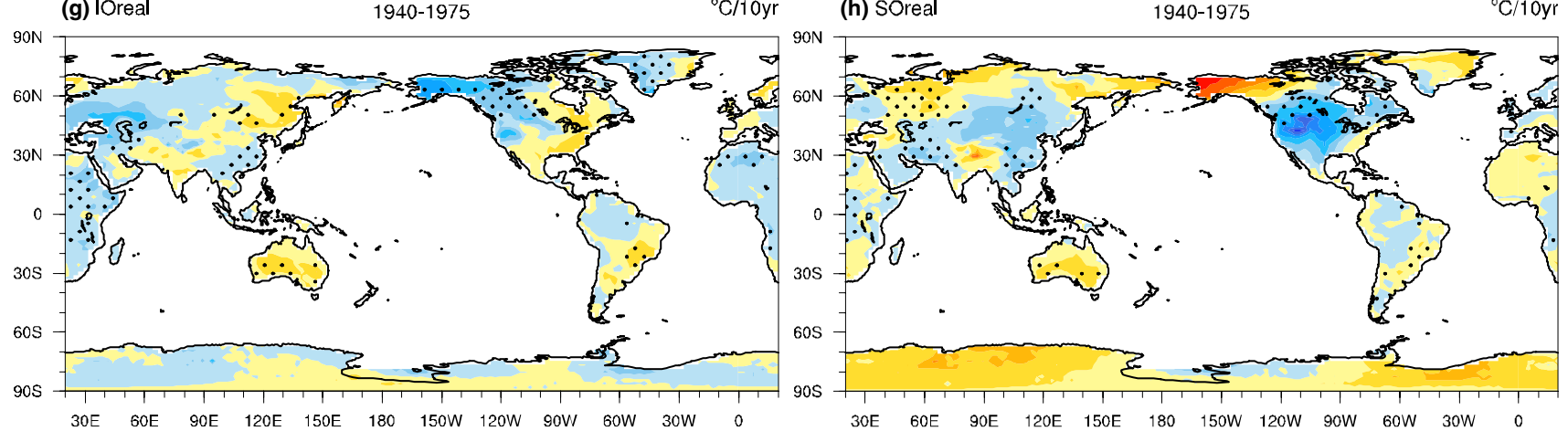

30E G0E $90 \mathrm{E}$ 120 $150 \mathrm{E} \quad 180$ 150W $120 \mathrm{~W}$ 90W $60 \mathrm{~W}$ 30W 0

Fig. 11 As in Fig. 9, but for 1940-1975 
(a) Observed

2001-2013

${ }^{\circ} \mathrm{C} / 10 \mathrm{yr}$

(b) Total Simulated

2001-2013

${ }^{\circ} \mathrm{C} / 10 \mathrm{yr}$
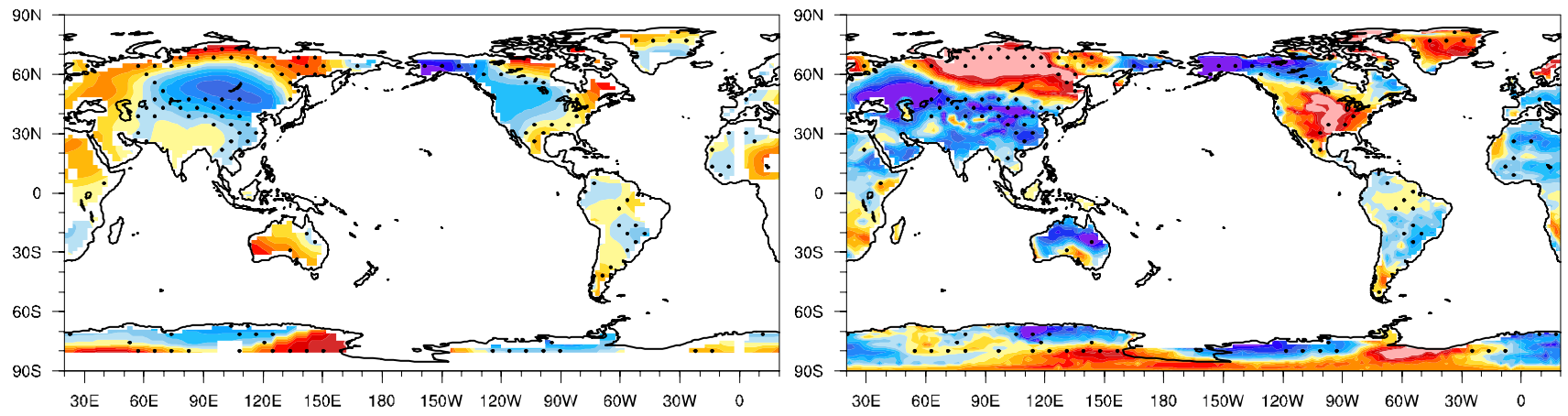

(c) NPreal

2001-2013

${ }^{\circ} \mathrm{C} / 10 \mathrm{yr} \quad$ (d) NAreal

2001-2013

${ }^{\circ} \mathrm{C} / 10 \mathrm{yr}$
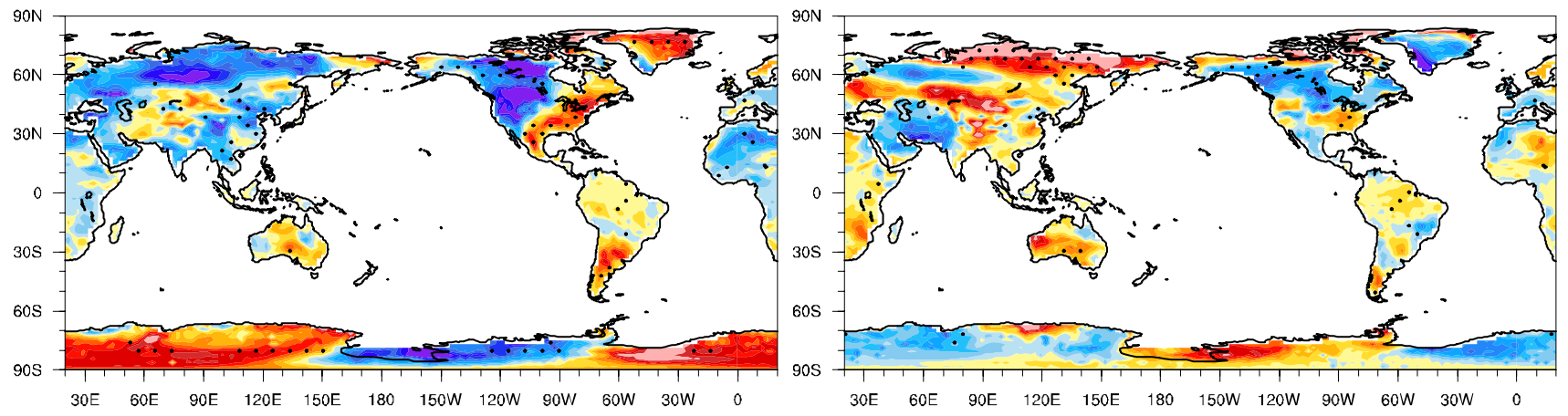

(e) TPreal

2001-2013

${ }^{\circ} \mathrm{C} / 10 \mathrm{yr} \quad$ (f) WPreal

2001-2013

${ }^{\circ} \mathrm{C} / 10 \mathrm{yr}$
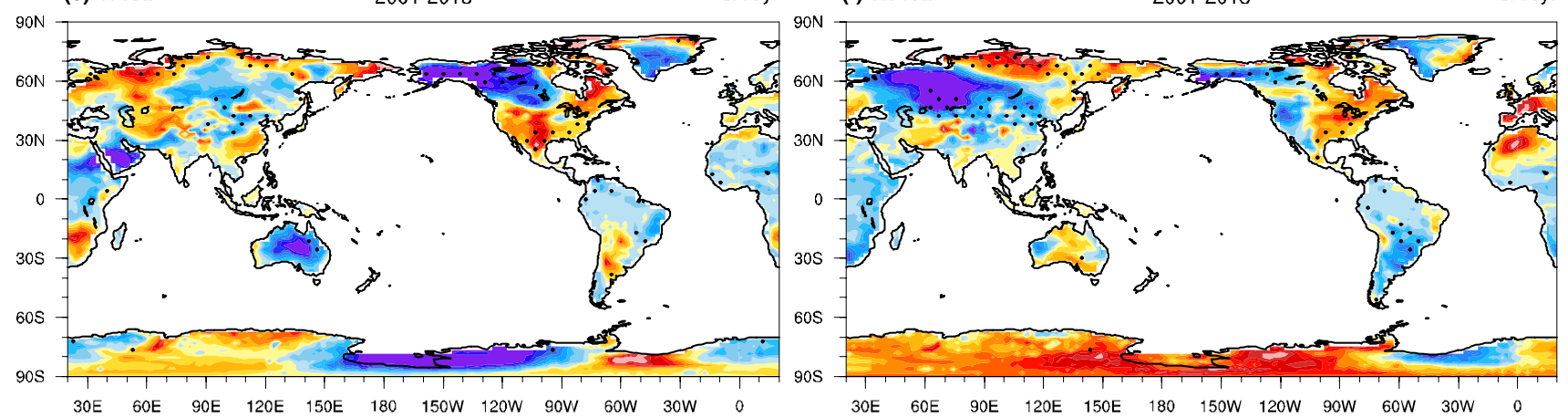

(g) IOreal

2001-2013

${ }^{\circ} \mathrm{C} / 10 y \mathrm{r}$

(h) SOreal

2001-2013

${ }^{\circ} \mathrm{C} / 10 \mathrm{yr}$
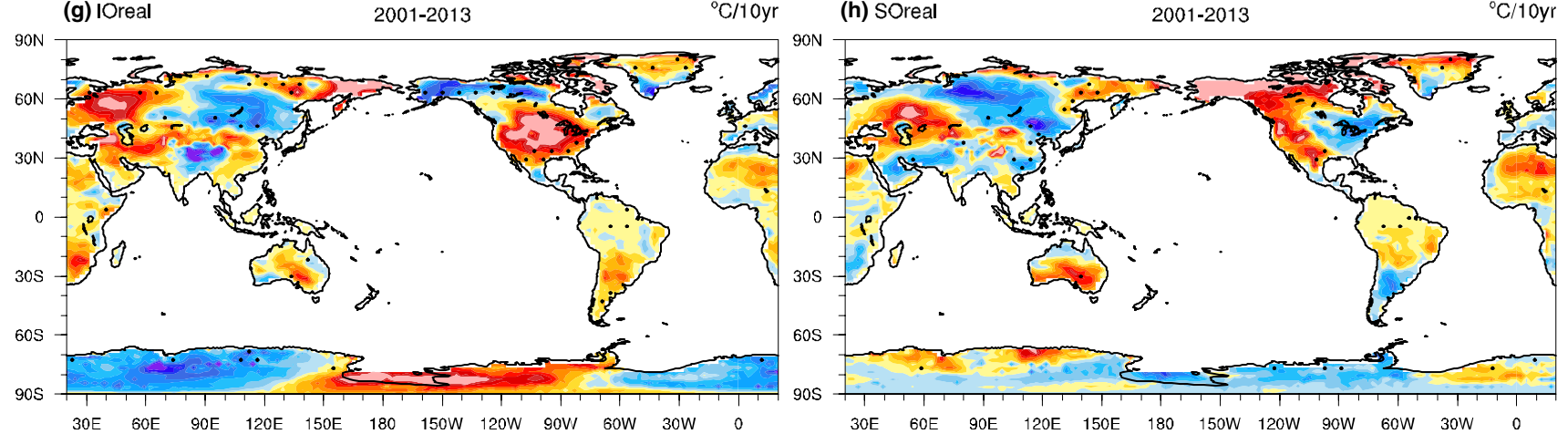

\begin{tabular}{lllllllll|llllllll}
-1.2 & -1.05 & -0.9 & -0.75 & -0.6 & -0.45 & -0.3 & -0.15 & 0 & 0.15 & 0.3 & 0.45 & 0.6 & 0.75 & 0.9 & 1.05 & 1.2
\end{tabular}

Fig. 12 As in Fig. 9, but for 2001-2013 
(a)

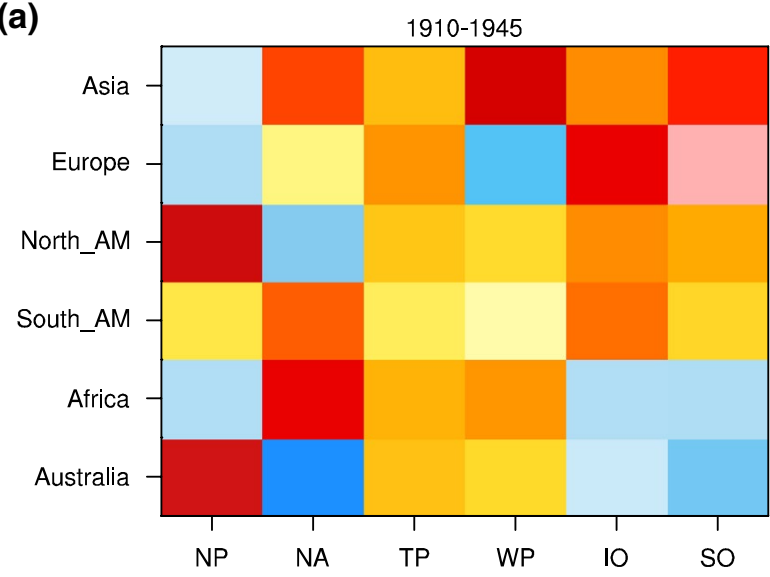

(b)

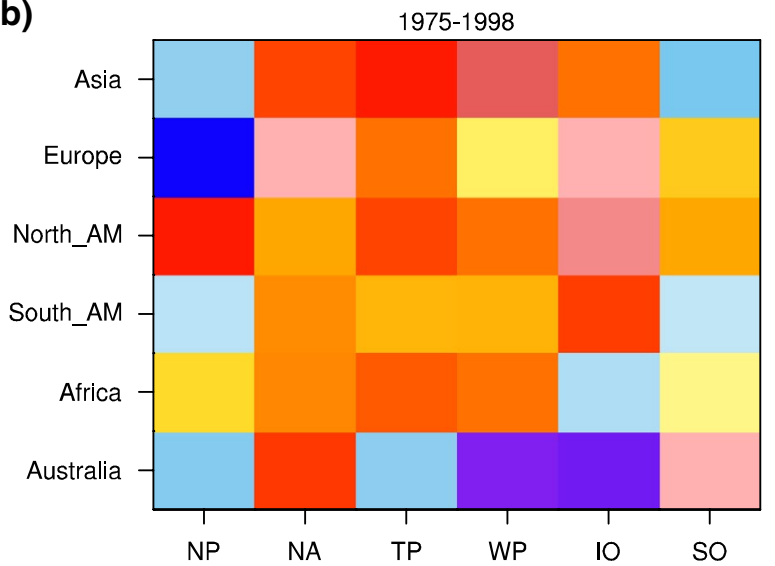

(c)

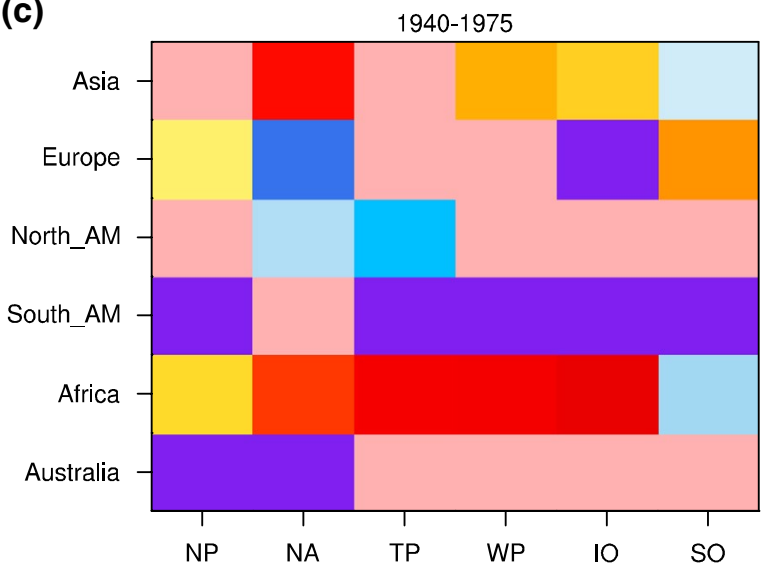

(d)

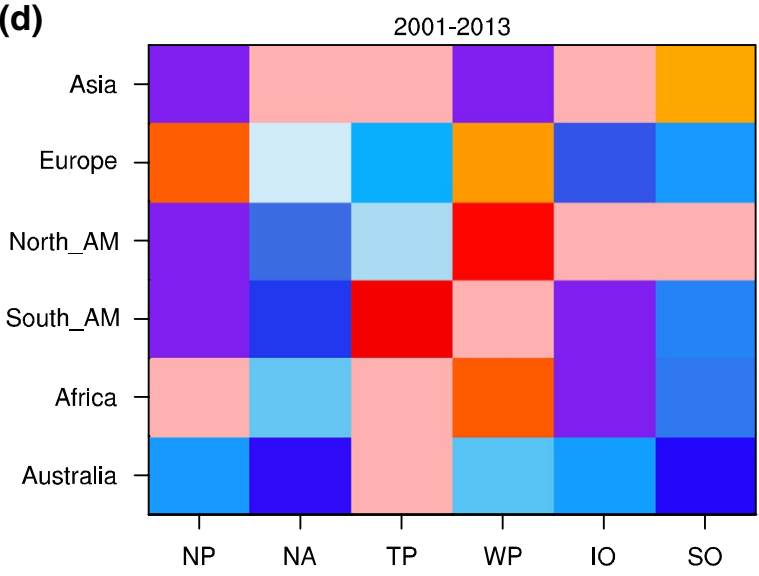

Fig. 13 Relative contribution rates of individual ocean SST forcing to SAT variability in different continents during a 1910-1945, b 1975-1998, c 1940-1975, and d 2001-2013. North_AM and South_AM denote North America and South America, respectively

During 1910-1945, the percentage of spatial sign consistency of the individual ocean SST forcing experiments varies between $23.8 \%$ (in NA) and $26.7 \%$ (in TP; Fig. 9), and the various experiments show explicit spatial differences in the SAT multidecadal trend. For 1975-1998, the percentage of sign consistency of the IO, NA, WP, and TP experiments with both the observation and the global SST forcing experiment are all above $41.5 \%$, which is higher than NP (33.8\%) and SO (33.6\%) (Fig. 10). This is also much higher than sign consistency in the former period. For 1940-1975, the percentage of sign consistency of the individual ocean SST forcing experiments is between $19.1 \%$ (in SO) and $26.7 \%$ (in WP). Despite only IO, NA, and WP simulating the weak cooling trend of this period, their sign consistency ( $20.7 \%$ in IO, $22.1 \%$ in NA, and $26.7 \%$ in WP) with observations and global SST simulations results are not very high (Fig. 11). The percentage of sign consistency for 2001-2013 is between $14.5 \%$ (in SO) and 19.5\% (in WP), which is lower than for the other three periods (Fig. 12). It can be inferred from the above results that impacts of individual ocean SST variation on LSAT spatial pattern have explicit regional characteristics.

\section{Summary and discussions}

We analyze the variability of the global and hemispheric GMST and LSAT multidecadal trends and quantify the direct effects of SST changes in individual ocean basins on the SAT multidecadal trend. During the rapid warming periods (1910-1945 and 1975-1998), the SAT multidecadal variability in NH and SH both have positive contributions to the GMST (LSAT) trend. The GMST multidecadal cooling trend between 1940 and 1975 is mainly caused by the effect of the NH SAT multidecadal variability on GMST and LSAT multidecadal variability. The NH SAT multidecadal variability promotes the GMST warming (cooling) trend, whereas the SH reduces the intensity of the warming (cooling) process in the GMST (LSAT) multidecadal trend compared with the NH. The NH SAT multidecadal variability contributes more strongly than $\mathrm{SH}$ SAT to the GMST and LSAT multidecadal trends between 1910 and 2013, except for 2001 and 2013, in which the NH SAT multidecadal variability contribution to the LSAT is weaker than that of SH SAT. The rate of GMST (LSAT) 
increasing is much higher in the latter period than the earlier period for both warming and cooling periods.

The experiments show that different regional SSTs all generate positive contributions to the GMST (LSAT) over the periods 1910-1945 and 1975-1998. Over the period 1910-1945, SO, NA, and WP contribute most to the GMST trend, whereas SST variations in IO, NA, and WP play the most important role in modulating the GMST trend during 1940-1975. The SST change in some regions (IO, NA, and WP) modify the cooling temperature trend as shown for GMST (LSAT) during 1940-1975, and TP and NP make positive contributions to the GMST multidecadal trend during 2001-2013. The SST variation in NA and WP make significant contributions to the whole 20th century GMST trend. At the continent scale, SST changes in the various oceans do not always play the same role in modifying GMST variability during the four periods. Compared with the SH continents, the simulated SAT trend of individual ocean SST forcing experiments contribute more to SAT variation in the NH continents during the four periods. The results also indicate that the processes by which the different oceans modulate SAT do not show periodic variabilities.

In this study, the boundaries between the selected key oceanic regions and the real ocean basins are not the same exactly. In some areas, there are certain small differences between the selected oceanic regions and the actual coastlines (Fig. 2). Take the Indian Ocean as an example, although there are small areas not covered in the selected oceanic region, the Persian Gulf and the near region for instance, which may cause some biases, the key domain including the main SST variability of Indian Ocean is already in the selected oceanic region (Fig. 2). Therefore, the biases caused by these areas would be relatively small. Similar situations occur in other basins.

It have to point out that the observed SAT trend from GISS dataset shows significant warming trend, while the simulated result shows slightly negative SAT trend over the equatorial East Pacific Ocean area (Fig. 4). The simulated SAT variability over the ocean area usually follows the regional SST variability inputted in model. The SST inputted in CESM_CAM5.3, the SST dataset from Hadley Centre sea ice and SST dataset version 1 (HadISST1; Rayner et al. 2003), shows the slight negative trend over the equatorial east Pacific Ocean area between 1910 and 2005 (not shown), which is associated with the simulated slight negative SAT trend over this region actually. While the observed SAT trend from GISS dataset is generated by not only SST but also by other factors in climate system, such as aerosol, volcanic eruptions (Jónsson et al. 1996; Ramaswamy et al. 2006; Sato et al. 1993; Santer et al. 2014), climate interaction and so on (Hurrell and Trenberth 1999; Vecchi et al. 2008). These probably are the reasons why the SAT trend in the GISS observed and model simulated results show discrepancy over the equatorial east Pacific Ocean.

The global multidecadal SAT trends are not modulated simply by oceanic surface temperature effects, but are also generated by multiple oceans via complex internal physical mechanisms and other factors, such as recent Arctic warming effects, nonlinear interactions within the climate system, external radiative forcing (Cohen et al. 2012; Meehl et al. 2013; Ramaswamy et al. 2006; Trenberth and Fasullo 2013; Wallace et al. 2014), ocean-atmosphere interaction (England et al. 2014), and ocean heat content change (Chen and Tung 2014, 2018). The influencing mechanisms as mentioned above and nonlinear effects cause more discrepancies between the model and observations during the cooling periods (1940-1975 and 2001-2013) compare with the warming periods (1940-1975 and 2001-2013). The underlying physical mechanisms associated with oceanic influence on the GMST trend will be pursued in our future work.

Previous studies have addressed the close linkage between GMST variability and the global oceans. It is essential to consider the effects of trans-basin variability, as well as the influence of the general atmospheric circulation, on the GMST trend to improve our understanding of the characteristics of GMST variability and its causes. In this study, we use a series of AGCM experiments to quantify the effect of SST on the GMST trend at the hemispheric scale and at the level of regional oceans. Although many important features have been captured in the AGCM simulations, as shown by the observations, there remain many nonlinear characteristics in the observations that AGCM and fully coupled model experiments cannot yet reveal. Hence, pacemaker experiments (i.e., partially coupled simulations that nudge the regional SST into the coupled model) are a necessary tool for further studies to determine the causes of regional climate anomalies.

Acknowledgements This work was jointly sponsored by the National Key R\&D Program of China (2016YFA0601801) and National Natural Science Foundation of China (NSFC) Project (41790474). We acknowledge the support of the Center for High Performance Computing and System Simulation, Qingdao Pilot National Laboratory for Marine Science and Technology. We are also grateful to NOAA/OAR/ ESRL PSD, Boulder, Colorado, USA, which Web site is https://www. esrl.noaa.gov/psd/ for providing GISTEMP data (1910-2017).

Open Access This article is distributed under the terms of the Creative Commons Attribution 4.0 International License (http://creativeco mmons.org/licenses/by/4.0/), which permits unrestricted use, distribution, and reproduction in any medium, provided you give appropriate credit to the original author(s) and the source, provide a link to the Creative Commons license, and indicate if changes were made. 


\section{References}

Chen XY, Wallace JM (2015) ENSO-like variability: 1900-2013. J Clim 28:9623-9641. https://doi.org/10.1175/JCLI-D-15-0322.1

Chen XY, Tung KK (2014) Varying planetary heat sink led to globalwarming slowdown and acceleration. Science 345:897-903. https://doi.org/10.1126/science.1254937

Chen XY, Tung KK (2018) Global surface warming enhanced by weak Atlantic overturning circulation. Nature 559:387-391. https://doi.org/10.1038/s41586-018-0320-y

Clement A, DiNezio P (2014) The tropical Pacific Ocean-Back in the driver's seat? Science 343:976-978. https://doi.org/10.1126/ science. 1248115

Cohen JL, Furtado JC, Barlow MA, Alexeev VA, Cherry JE (2012) Arctic warming, increasing snow cover and widespread boreal winter cooling. Environ Res Lett 7:014007. https://doi. org/10.1088/1748-9326/7/1/014007

Dai A, Fyfe JC, Xie SP, Dai X (2015) Decadal modulation of global surface temperature by internal climate variability. Nat Clim Change 5(6):555-559. https://doi.org/10.1038/nclimate2605

Easterling DR, Wehner MF (2009) Is the climate warming or cooling? Geophys Res Lett 36:8. https://doi.org/10.1029/2009GL037810

England MH, McGregor S, Spence P, Meehl GA, Timmermann A, Cai W, Gupta AS, McPhaden MJ, Purich A, Santoso A (2014) Recent intensification of wind-driven circulation in the Pacific and the ongoing warming hiatus. Nat Clim Change 4(3):222-227. https ://doi.org/10.1038/nclimate2106

Fyfe JC, Gillett NP (2014) Recent observed and simulated warming. Nat Clim Change 4(3):150-151

Hansen J, Ruedy R, Sato M, Lo K (2010) Global surface temperature change. Rev Geophys. https://doi.org/10.1029/2010RG000345

Hurrell JW, Holland MM, Gent PR, Ghan S, Kay JE, Kushner PJ, Lamarque J-F, Large WG, Lawrence D, Lindsay K, Lipscomb WH, Long MC, Mahowald N, Marsh DR, Neale RB, Rasch P, Vavrus S, Vertenstein M, Bader D, Collins WD, Hack JJ, Kiehl J, Marshall S (2013) The community earth system model: a framework for collaborative research. Bull Am Meteorol Soc 94:1339-1360

Hurrell JW, Trenberth KE (1999) Global sea surface temperature analyses: multiple problems and their implications for climate analysis, modeling, and reanalysis. Bull Am Meteorol Soc 80:2661-2678. https://doi.org/10.1175/1520-0477(1999)0802.0.CO;2

IPCC (2007) Summary for policymakers of climate change 2007: the physical science basis. Contribution of Working Group I to the Fourth Assessment Report of the Intergovernmental Panel on Climate Change (M). Cambridge University Press, Cambridge

Jónsson HH, Wilson JC, Brock CA, Dye JE, Ferry GV, Chan KR (1996) Evolution of the stratospheric aerosol in the northern hemisphere following the June 1991 volcanic eruption of Mount Pinatubo: role of tropospheric - stratospheric exchange and transport. J Geophys Res Atmos 101:1553-1570. https://doi.org/10.1029/95jd0 2932

Knight J, Kennedy JJ, Folland C, Harris G, Jones GS, Palmer M, Parker D, Scaife A, Stott P (2009) Do global temperature trends over the last decade falsify climate predictions. Bull Am Meteorol Soc 90:22-23

Kosaka Y, Xie SP (2013) Recent global-warming hiatus tied to equatorial Pacific surface cooling. Nature 501:403-407. https://doi. org/10.1038/nature12534

Kosaka Y, Xie SP (2016) The tropical Pacific as a key pacemaker of the variable rates of global warming. Nat Geosci 9:669-673. https ://doi.org/10.1038/ngeo2770

Li JP, Sun C, Jin F-F (2013) NAO implicated as a predictor of Northern Hemisphere mean temperature multidecadal variability. Geophys Res Lett 40:5497-5502. https://doi.org/10.1002/2013gl057877
Li JP, Sun C, Ding RQ (2018) Decadal coupled ocean-atmosphere interaction in North Atlantic and global warming hiatus. Special Publications of the International Union of Geodesy and Geophysics. Cambridge University Press, Cambridge

Li X, Xie SP, Gille ST, Yoo C (2016) Atlantic-induced pan-tropical climate change over the past three decades. Nat Clim Change 6:275-279. https://doi.org/10.1038/nclimate2840

Li Y, Li JP, Zhang WJ, Zhao X, Xie F, Zheng F (2015) Ocean dynamical processes associated with the tropical Pacific cold tongue mode. J Geophys Res Oceans 120:6419-6435. https://doi. org/10.1002/2015JC010814

Li Y, Li JP, Zhang WJ, Chen Q, Feng J, Zheng F, Wang W, Zhou $X$ (2017) Impacts of the tropical Pacific cold tongue mode on ENSO diversity under global warming. J Geophys Res: Oceans 122:8524-8542. https://doi.org/10.1002/2017JC013052

Luo JJ, Sasaki W, Masumoto Y (2012) Indian ocean warming modulates pacific climate change. Proc Natl Acad Sci USA 109:18701-18706. https://doi.org/10.1073/pnas.1210239109

Maher N, Gupta AS, England MH (2014) Drivers of decadal hiatus periods in the 20th and 21st centuries. Geophys Res Lett 41:5978-5986. https://doi.org/10.1002/2014GL060527

Mantua NJ, Hare SR, Zhang Y, Wallace JM, Francis RC (1997) A Pacific interdecadal climate oscillation with impacts on salmon production. Bull Am Meteorol Soc 78:1069-1080. https://doi.org/10.1175/1520-0477(1997)078\%3c1069:APICO $\mathrm{W} \% 3 \mathrm{e} 2.0 . \mathrm{CO} ; 2$

McGregor S, Timmermann A, Stuecker MF, England MH, Merrifield M, Jin F-F, Chikamoto Y (2014) Recent Walker circulation strengthening and Pacific cooling amplified by Atlantic warming. Nat Clim Change 4:888-892. https://doi.org/10.1038/nclim ate 2330

Meehl GA, Arblaster JM, Fasullo JT, Hu A, Trenberth KE (2011) Model-based evidence of deep-ocean heat uptake during surface-temperature hiatus periods. Nat Clim Change 1:360-364. https://doi.org/10.1038/nclimate1229

Meehl GA, Hu A, Arblaster JM, Fasullo J, Trenberth KE (2013) Externally forced and internally generated decadal climate variability associated with the Interdecadal Pacific Oscillation. J Clim 26:7298-7310. https://doi.org/10.1175/jcli-d-12-00548.1

Meehl GA, Washington WM, Arblaster JM, Hu A, Teng H, Tebaldi C, Sanderson BN, Lamarque J-F, Conley A, Strand WG, White JB III (2012) Climate system response to external forcings and climate change projections in CCSM4. J Clim 25:3661-3683. https://doi.org/10.1175/JCLI-D-11-00240.1

Meinshausen M, Vogel E, Nauels A, Lorbacher K, Meinshausen N, Etheridge DM, Fraser PJ, Montzka SA, Rayner PJ, Trudinger CM, Krummel PB, Beyerle U, Canadell JG, Daniel JS, Enting IG, Law RM, Lunder CR, O’Doherty S, Prinn RG, Reimann S, Rubino M, Velders GJM, Vollmer MK, Wang RHJ (2017) Historical greenhouse gas concentrations for climate modelling (CMIP6). Geosci Model Dev 10:2057-2116. https://doi. org/10.5194/gmd-10-2057-2017

Minobe S, Mantua N (1999) Interdecadal modulation of interannual atmospheric and oceanic variability over the North Pacific. Prog Oceanogr 43:163-192. https://doi.org/10.1016/S0079 -6611(99)00008-7

Mochizuki T, Kimoto M, Watanabe M, Chikamoto Y, Ishii M (2016) Interbasin effects of the Indian Ocean on Pacific decadal climate change. Geophys Res Lett 43:7168-7175. https://doi. org/10.1002/2016GL069940

Nan S, Li JP (2003) The relationship between the summer precipitation in the Yangtze River valley and the boreal spring Southern Hemisphere annular mode. Geophys Res Lett. https://doi. org/10.1029/2003GL018381

Nidheesh AG, Lengaigne M, Vialard J, Unnikrishnan AS, Dayan $H$ (2013) Decadal and long-term sea level variability in the 
tropical Indo-Pacific Ocean. Clim Dyn 41:381-402. https://doi. org/10.1007/s00382-012-1463-4

Nieves V, Willis JK, Patzert WC (2015) Recent hiatus caused by decadal shift in Indo-Pacific heating. Science 349:532-535. https ://doi.org/10.1126/science.aaa4521

Power S, Casey T, Folland C, Colman A, Mehta V (1999) Interdecadal modulation of the impact of ENSO on Australia. Clim Dyn 15:319-324. https://doi.org/10.1007/s003820050284

Qiang XM, Yang XQ (2013) Relationship between the first rainy season precipitation anomaly in South China and the sea surface temperature anomaly in the Pacific. Chin J Geophys 56:25832593. https://doi.org/10.6038/cjg20130808 (in Chinese)

Ramaswamy V, Schwarzkopf MD, Randel WJ, Santer BD, Soden BJ, Stenchikov GL (2006) Anthropogenic and natural influences in the evolution of lower stratospheric cooling. Science 311:11381141. https://doi.org/10.1126/science. 1122587

Rayner NA, Parker DE, Horton EB, Folland CK, Alexander LV, Rowell DP, Kent EC, Kaplan A (2003) Global analyses of sea surface temperature, sea ice, and night marine air temperature since the late nineteenth century. J Geophys Res 108:4407. https://doi. org/10.1029/2002jd002670

Santer BD, Bonfils C, Painter JF, Zelinka MD, Mears C, Solomon S, Schmidt GA, Fyfe JC, Cole JNS, Nazarenko L, Taylor KE, Wentz FJ (2014) Volcanic contribution to decadal changes in tropospheric temperature. Nat Geosci 7:185-189. https://doi. org/10.1038/ngeo2098

Sato M, Hansen JE, McCormick MP, Pollack JB (1993) Stratospheric aerosol optical depths, 1850-1990. J Geophys Res: Atmospheres 98:22987-22994. https://doi.org/10.1029/93jd02553

Sillmann J, Donat MG, Fyfe JC, Zwiers FW (2014) Observed and simulated temperature extremes during the recent warming hiatus. Environ Res Lett 9(6):064023. https://doi.org/10.1088/17489326/9/6/064023

Smith D (2013) Oceanography: has global warming stalled? Nat Clim Change 3:618-619

Solomon S, Rosenlof KH, Portmann RW, Daniel JS, Davis SM, Sanford TJ, Plattner GK (2010) Contributions of stratospheric water vapor to decadal changes in the rate of global warming. Science 327:1219-1223. https://doi.org/10.1126/science.1182488

Stocker TF, Qin D, Plattner GK, Tignor M, Allen SK, Boschung J, Nauels A, Xia Y, Bex V, Midgley PM (2014) Climate change 2013: the physical science basis. Cambridge University Press, Cambridge

Sun C, Li JP, Jin FF (2015) A delayed oscillator model for the quasiperiodic multidecadal variability of the NAO. Clim Dyn 45:20832099. https://doi.org/10.1007/s00382-014-2459-z

Sun C, Kucharski F, Li JP, Jin F-F, Kang IS, Ding R (2017) Western tropical Pacific multidecadal variability forced by the Atlantic multidecadal oscillation. Nat Commun 8:15998. https://doi. org/10.1038/ncomms 15998

Timmermann A, McGregor S, Jin F-F (2010) Wind effects on past and future regional sea level trends in the southern Indo-Pacific. J Clim 23:4429-4437. https://doi.org/10.1175/2010JCLI3519.1

Trenberth KE (2015) Has there been a hiatus? Science 349:691-692. https://doi.org/10.1126/science.aac9225

Trenberth KE, Hurrell JW (1994) Decadal atmosphere-ocean variations in the Pacific. Clim Dyn 9:303-319. https://doi.org/10.1007/ BF00204745

Trenberth KE, Fasullo JT (2013) An apparent hiatus in global warming? Earth's Future 1:19-32. https://doi.org/10.1002/2013ef0001 65

Vecchi GA, Clement A, Soden BJ (2008) Examining the tropical Pacific's response to global warming. Eos Trans AGU 89:81-83. https ://doi.org/10.1029/2008EO090002

Wallace JM, Held IM, Thompson DW, Trenberth KE, Walsh JE (2014) Global warming and winter weather. Science 343:729-730. https ://doi.org/10.1126/science.343.6172.729

Xie SP, Kosaka Y (2017) What caused the global surface warming hiatus of 1998-2013? Curr Clim Change Rep 3:128-140. https:// doi.org/10.1007/s40641-017-0063-0

Xie SP, Kosaka Y, Okumura YM (2016) Distinct energy budgets for anthropogenic and natural changes during global warming hiatus. Nat Geosci 9:29-33. https://doi.org/10.1038/ngeo2581

Xing N, Li JP, Wang LN (2017) Multidecadal trends in large-scale annual mean SATa based on CMIP5 historical simulations and future projections. Engineering 3:136-143. https://doi. org/10.1016/J.ENG.2016.04.011

Yao SL, Luo JJ, Huang G, Wang P (2017) Distinct global warming rates tied to multiple ocean surface temperature changes. Nat Clim Change 7:486-491. https://doi.org/10.1038/nclimate3304

Zhang WJ, Li JP, Zhao X (2010) Sea surface temperature cooling mode in the Pacific cold tongue. J Geophys Res 115:C12042. https://doi. org/10.1029/2010JC006501

Zhang Y, Wallace JM, Battisti DS (1997) ENSO-like interdecadal variability: 1900-93. J Clim 10:1004-1020. https://doi. org/10.1175/1520-0442(1997)010\%3c1004:Eliv\%3e2.0.Co;2

Zuo B, Li JP, Sun C, Zhou X (2019) A new statistical method for detecting trend turning. Theor Appl Climatol Online. https://doi. org/10.1007/s00704-019-02817-9

Publisher's Note Springer Nature remains neutral with regard to jurisdictional claims in published maps and institutional affiliations. 